\title{
Cancer-associated adipocytes: emerging supporters in breast cancer
}

\author{
Chongru Zhao ${ }^{\dagger}$, Min Wu ${ }^{\dagger}$, Ning Zeng ${ }^{\dagger}$, Mingchen Xiong, Weijie Hu, Wenchang Lv, Yi Yi, Qi Zhang ${ }^{*}$ and \\ Yiping $\mathrm{Wu}^{*}$ (D)
}

\begin{abstract}
Breast cancer (BC) is a malignant breast tumor confronted with high invasion, metastasis and recurrence rate, and adipocytes are the largest components in breast tissue. The aberrant adipocytes, especially the BC-neighbored cancer-associated adipocytes (CAAs), are found in the invasive front of BC. CAAs present a vicious phenotype compared with mature mammary adipocytes and mediate the crosstalk network between adipocytes and BC cells. By releasing multiple adipokines such as leptin, adiponectin, interleukin (IL)-6, chemokine ligand 2 (CCL2) and chemokine ligand 5 (CCL5), CAAs play essential roles in favor of proliferation, angiogenesis, dissemination, invasion and metastasis of $B C$. This article reviews the recent existing CAAs studies on the functions and mechanisms of adipocytes in the development of BC, including adipokine regulating, metabolic reprogramming, extracellular matrix (ECM) remodeling, microRNAs (miRNAs) and immune cell adjusting. Besides, adipocyte secretome and cellular interactions are implicated in the intervention to BC therapy and autologous fat grafting of breast reconstruction. Therefore, the potential functions and mechanisms of CAAs are very important for unveiling BC oncogenesis and progress. Deciphering the complex network between CAAs and BC is critical for designing therapeutic strategies and achieving the maximum therapeutic effects of $\mathrm{BC}$.
\end{abstract}

Keywords: Breast cancer, Adipocytes, Cancer-associated adipocytes, Adipokines, Breast cancer therapy

\section{Background}

Breast cancer (BC) is the most frequently diagnosed malignancy and the major cause of cancer-related death in females worldwide [1]. The reason is that $\mathrm{BC}$ is confronted with high invasion, metastasis and recurrence rate, especially the metastatic capacity to the brain and lungs [2]. Adipose tissue plays a crucial role as an energy storage depot and can act as endocrine cells to produce various bioactive substances [3]. Epidemiological and etiological evidence has shown that the aberrant adipose state such as obesity is a significant risk and negative prognosis factor for BC [4]. Besides, mounting studies have confirmed that adipocytes

\footnotetext{
*Correspondence: 806430787@qq.com; tongjiplastic@163.com

${ }^{\dagger}$ Chongru Zhao, Min Wu and Ning Zeng contributed equally to this work. Department of Plastic Surgery, Tongji Hospital, Tongji Medical College, Huazhong University of Science and Technology, 1095 Jiefang Avenue, Wuhan 430030, Hubei, China
}

adjacent to invasive cancer cells, which are referred to as cancer-associated adipocytes (CAAs), are involved in the progression of $\mathrm{BC}$ [5]. Thus, the aberrant adipose tissue, especially the $\mathrm{BC}$-neighbored CAAs, is a $\mathrm{BC}$ hallmark which has been confirmed in human $B C$ samples [6].

The breast is a unique and dynamic organ that changes in anatomy and function continuously throughout the whole life. Based on the anatomical distribution, a fully differentiated breast is composed of two compartments: the epithelial compartment that consists of glands with branched ducts and lobuloalveolar differentiated units; and the connective tissue compartment, commonly known as the breast fat pad, is primarily constituted by adipose tissue [7]. Normally, mature adipocytes and epithelial cells are separated by the basement membrane, limiting the possibility of interaction between the two cells. However, BC cells will directly expose to the tumor microenvironment (TME)

\section{BMC}

(c) The Author(s). 2020 Open Access This article is licensed under a Creative Commons Attribution 4.0 International License, which permits use, sharing, adaptation, distribution and reproduction in any medium or format, as long as you give appropriate credit to the original author(s) and the source, provide a link to the Creative Commons licence, and indicate if changes were made. The images or other third party material in this article are included in the article's Creative Commons licence, unless indicated otherwise in a credit line to the material. If material is not included in the article's Creative Commons licence and your intended use is not permitted by statutory regulation or exceeds the permitted use, you will need to obtain permission directly from the copyright holder. To view a copy of this licence, visit http://creativecommons.org/licenses/by/4.0/ The Creative Commons Public Domain Dedication waiver (http://creativecommons.org/publicdomain/zero/1.0/) applies to the data made available in this article, unless otherwise stated in a credit line to the data. 
containing adipocytes when they break through the basement membrane [8]. As a major cellular component of the breast tissue stroma, adipocytes are involved in all $\mathrm{BC}$ processes, consequently promoting cancer progression. However, the highly complex interaction orchestrated by CAAs and $\mathrm{BC}$ cells has not been completely elucidated.

The interplay between the neighboring CAAs and $\mathrm{BC}$ ultimately results in shaping the TME towards the oncogenic-driven state in favor of proliferation, angiogenesis, tumor dissemination, invasion and metastasis (Fig. 1). This article has reviewed the recent existing studies on the mechanisms of adipocytes in the development of $\mathrm{BC}$, including adipokines regulating, metabolic reprogramming, extracellular matrix (ECM) remodeling, microRNAs (miRNAs) and immune cells adjusting. It also emphasized the clinical implication of the resistant effect of adipocytes on $\mathrm{BC}$ therapy, and the potential effect of autologous fat grafting after mastectomy on $\mathrm{BC}$ recurrence. An in-depth understanding of the mechanisms of adipocytes in BC development will provide better insight into CAA-associated tumorigenesis and screen novel strategies for therapeutic interventions of $\mathrm{BC}$.

\section{Adipocytes and breast cancer}

Adipose tissue plays an important physiological role as a metabolically active storage compartment and endocrine organ due to its diverse abilities in secreting various adipokines [9]. It has aroused great interest in understanding the development and renewal of adipose tissue under normal or pathological conditions, such as obesity and $\mathrm{BC}$. Adipocytes constitute the main cell component of ECM in $\mathrm{BC}[10,11]$. CAAs are not only found adjacent to $\mathrm{BC}$ cells but also communicate with $\mathrm{BC}$ cells by releasing various factors that can mediate local and systemic effects. Adipose tissue dysfunction has been linked to accelerated growth and survival of $\mathrm{BC}$ cells. Numerous studies have confirmed that CAA-BC cell crosstalk can promote $\mathrm{BC}$ progression and metastasis through multiple secreted adipokines, and their role in remodeling tumor characteristics.

\section{Mature adipocytes vs. cancer-associated adipocytes}

Physiologically, adipocytes that constitute breast tissue and encapsulate around the mammary gland, can maintain normal breast morphology and the energy balance. These mature adipocytes are mainly white adipocytes (WAT), with round shape, large unilocular lipid droplets and endocrine functions $[12,13]$. CAAs mainly locate at the invasive front of breast tumors, namely adjacent to BC cells. Notably, compared with mature adipocytes, CAAs possess smaller cell sizes, irregular shapes, and small/dispersed lipid droplets [14, 15]. Moreover, CAAs exhibit a modified phenotype characterized by the loss of lipid content, decrease in late adipocyte differentiation markers and overexpression of inflammatory cytokines

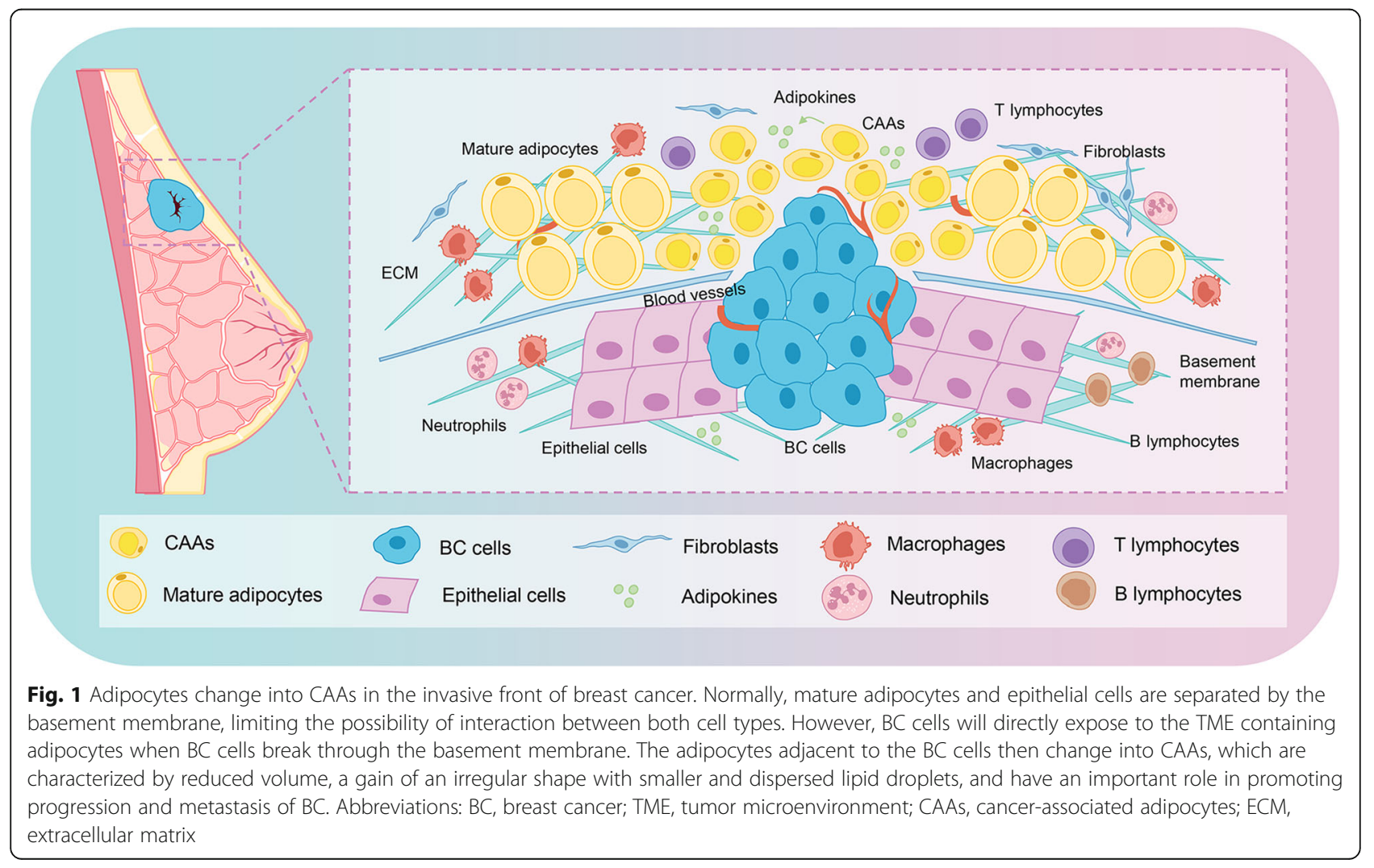


and proteases [14]. In terms of adipokines, secretions of leptin, adiponectin, interleukin (IL)-6, chemokine ligand 2 (CCL2), chemokine ligand 5 (CCL5) and other cytokines in CAAs are more aberrant than that in mature adipocytes [5, 16]. Most importantly, compared with the distant mature adipocytes, CAAs could gain a more vicious phenotype, and enhance $\mathrm{BC}$ growth and metastasis, by a less physical barrier and more aggressive secretome of adipokines (as described in Table 1).

\section{Adipokines}

Adipocytes can secrete more than 600 kinds of metabolites, hormones and cytokines, collectively known as adipokines. These adipokines are involved in the regulation of multiple life activities, including fat distribution, insulin secretion, energy consumption, inflammatory reaction [5]. Adipokine-mediated crosstalk network between adipocytes and $\mathrm{BC}$ cells favors the proliferation, survival and metastasis of $\mathrm{BC}$ [17]. Here, we especially focus on the emerging roles of CAA-derived leptin, adiponectin, IL-6, CCL2, CCL5 and other key adipokines in this reciprocal crosstalk. Uncovering the functions and the mechanisms of CAAderived adipokines are essential to understand the $\mathrm{BC}$ behavior and the establishment of accurate interventions.

\section{Leptin}

Leptin, a hormone with a molecular weight of about 16 $\mathrm{kDa}$, is encoded by the LEP gene on human chromosome 7 and is mainly synthesized and secreted by adipocytes. By binding to its receptor ObR, leptin exerts diverse biological functions including proliferation, differentiation, inflammation and nutrient absorption [18].
Leptin is correlated with $\mathrm{BC}$ occurrence and tumor behavior. There is a positive correlation between the elevated serum leptin level and $\mathrm{BC}$ risk, especially in obese or postmenopausal women $[19,20]$. Furthermore, the leptin expression was increased in adipose tissue in the invasive front compared with that in the distant $\mathrm{BC}$ site [21]. In addition, the leptin production in CAAs was increased compared with mature adipocytes, suggesting that leptin was involved in the interaction of adipocytes and BC cells [13]. Leptin may modulate many aspects of breast tumorigenesis from initiation, growth to metastatic progression by autocrine, endocrine and paracrine manner.

Many studies have advocated the importance of leptin in promoting BC growth $[5,13]$. In addition, the crucial role of leptin in the invasion and metastasis-associated events of $\mathrm{BC}$ is also in focus. The results from Wei et al. showed that leptin could promote epithelial-mesenchymal transition (EMT) in BC cell lines via up-regulating the expression of pyruvate kinase M2 (PKM2) and activating the PI3K/AKT signaling pathway in vitro and in vivo [22]. Using MCF-7 and MDA-MB-231 cell lines, Juárez-Cruz also confirmed that leptin could enhance secretion of ECM remodelers by activating focal adhesion kinase (FAK) through an Src- and STAT3-dependent canonical pathway, suggesting that leptin was associated with the establishment of a more aggressive invasive phenotype in $\mathrm{BC}$ cells [23]. When $\mathrm{BC}$ cell lines cocultured with mature adipocytes, adipocyte-derived leptin and IL-6 promoted local invasion and eventually metastasis of tumor cells via activation of lysyl hydroxylase 2 (PLOD2) [24]. Moreover, adipocyte-derived leptin was approved to propel self-

Table 1 Mature adipocytes vs. cancer-associated adipocytes

\begin{tabular}{|c|c|c|}
\hline & Mature adipocytes & CAAs \\
\hline Definition & $\begin{array}{l}\text { Adipose tissue occupies } 56 \% \text { of the non-lactating } \\
\text { breast tissue and } 35 \% \text { of lactating breast tissue. } \\
\text { Adipocytes that constitute breast tissue are WAT, } \\
\text { with lipid-storage and endocrine functions. }\end{array}$ & $\begin{array}{l}\text { Adipocytes at the invasive front of breast tumor exhibit a } \\
\text { modified phenotype, a loss of lipid content, a decrease in } \\
\text { late adipocyte differentiation markers and overexpression } \\
\text { of inflammatory cytokines and proteases. }\end{array}$ \\
\hline Location & $\begin{array}{l}\text { Mature adipocytes encapsulate around the mammary } \\
\text { gland; } \\
\text { Adipocytes are separated with epithelial cells by } \\
\text { the basement membrane. }\end{array}$ & $\begin{array}{l}\text { Locate at the invasive front of breast tumor; } \\
\text { Adjacent to BC cells. }\end{array}$ \\
\hline Morphology & $\begin{array}{l}\text { Normal cell size; } \\
\text { Round shape; } \\
\text { Large unilocular lipid droplets. }\end{array}$ & $\begin{array}{l}\text { Smaller cell size; } \\
\text { Irregular shape with smaller size; } \\
\text { Smaller and dispersed lipid droplets. }\end{array}$ \\
\hline Function & $\begin{array}{l}\text { Maintain normal breast morphology; } \\
\text { With endocrine functions and maintain the energy } \\
\text { balance; } \\
\text { Normally expression of adipokines, including leptin, } \\
\text { adiponectin, IL-6, CCL2, CCL5 and other cytokines. }\end{array}$ & $\begin{array}{l}\text { Aberrantly expressional secretion of adipokines, including } \\
\text { leptin, adiponectin, IL-6, CCL2, CCL5 and other cytokines. }\end{array}$ \\
\hline Impact on breast cancer & $\begin{array}{l}\text { The promoting effect of adipocytes on } B C \text { is far less } \\
\text { compared with CAAs; } \\
\text { The risk of BC might increase under the condition } \\
\text { of obesity. }\end{array}$ & $\begin{array}{l}\text { The interaction between CAAs and BC cells may directly affect } \\
\text { their morphology and function; } \\
\text { CAAs could promote BC cell proliferation, viability, migration } \\
\text { and invasion in vitro, and could enhance tumor growth and } \\
\text { metastasis in vivo xenograft studies in a paracrine manner. }\end{array}$ \\
\hline
\end{tabular}


renewal of $\mathrm{BC}$ stem cells and chemoresistance via activating JAK/STAT3-regulated fatty acid $\beta$-oxidation (FAO) in mouse breast tumors in vivo [25]. Local adipocytes enable $\mathrm{BC}$ progression via leptin-regulated immune cells. Li et al. investigated that leptin triggered macrophage-related cytokine IL-18 production via NF- $\kappa B / N F-\kappa B 1$ signaling in tumor-associated macrophages (TAMs), while via PI3KAKT/ATF-2 signaling in BC cells, possibly contributing to $\mathrm{BC}$ invasion and metastasis [26]. Leptin enriched in mammary adipocytes could downregulate $\mathrm{CD}^{+} \mathrm{T}$ cell effector functions through activating STAT3-FAO and inhibiting glycolysis, leading to inhibition of breast tumor development [27].

\section{Adiponectin}

Adiponectin, a $30 \mathrm{kDa}$ peptide hormone encoded by the AdipoQ gene, plays a major role in glucose metabolism and energy homeostasis. Adiponectin has been confirmed to be associated with diabetes, inflammation and cancer development [28]. Adiponectin act mainly through two adiponectin receptor subtypes, AdipoR1 and AdipoR2, which are identified in mammary tissues obtained from both humans and animals [29]. However, the role of adiponectin receptors in $\mathrm{BC}$ development remains to be established. Tuna et al. measured expression levels of adiponectin, AdipoR1 and AdipoR2 proteins in the mammary fat pad, mammary tumor (MT) and serum adiponectin levels from 74 weeks old mice with and without MT [29]. The results showed that protein expression levels of adiponectin and AdipoR1 were significantly lower in MTs compared to control tissues, revealing that AdipoR1, rather than AdipoR2, might be dominant in adiponectin signaling in MT development [29]. Further studies are still necessary to characterize the roles of these two receptors in tumor development. Notably, reports have shown that adiponectin levels in adipose tissue of $\mathrm{BC}$ were significantly lower than that of normal breast adipose tissue, while the adiponectin receptor mRNA expression levels were significantly increased [6]. As the secretion of adiponectin was decreased in CAAs, it implied the potential relationship between adiponectin and its related signaling proteins in anti-BC activities.

Adiponectin could negatively regulate cancer cell growth via regulating inflammatory signaling molecules, including Erk1/2, Akt, tumor necrosis factor (TNF)- $\alpha$, IL-1 $\beta, N F-\kappa B, I L-6$, IL-8 and CCL2 [20]. Autophagy is a basic vacuolar, lysosomal degradation process known to help to prevent the accumulation of damaged proteins and organelles, recycling cytoplasmic constituents, and maintaining cellular homeostasis [30]. CAAs are of functional diversity and may enhance malignant behavior by inducing the senescence of adipocytes via autophagy, such as transforming growth factor (TGF)- $\beta$, adiponectin, or hypoxia-inducible factor (HIF)- $1 \alpha$-dependent autophagy [31]. In $\mathrm{BC}$, the activation of autophagic flux is an indicator of tumor regulation. AMP-activated protein kinase (AMPK) is a key energy sensor which can be modulated by cytokines such as leptin and adiponectin, and can promote autophagy and regulate cellular metabolism in maintaining energy homeostasis [32]. Chung et al. presented that adiponectin was a potent cytotoxicautophagy inducer leading to $\mathrm{BC}$ inhibition and the mechanistic underpinnings involved in modulation of the STK11/LKB1 and AMPK-ULK1 axis [30]. Adiponectin markedly decreased growth and increased apoptosis in $\mathrm{BC}$ cells treated with various chemotherapeutic agents [30]. ULK1 is an autophagy-initiating kinase. Under nutrient sufficiency, a high mammalian target of rapamycin (mTOR) activity prevented ULK1 activation by phosphorylating ULK1 on Ser 757, thus destroying the interaction between ULK1 and AMPK [33]. Activated AMPK suppresses mTOR complex 1 (mTORC1) mediated activation of tuberous sclerosis 2 (TSC2) or inactivation of regulatory-associated protein of mTOR (Raptor) [34, 35]. The adipocyte-secreted adiponectin is a potent inducer of cytotoxic autophagy for $\mathrm{BC}$ inhibition, showing the therapeutic efficacy as a single agent or auxiliary anti-tumor substance.

Besides, adiponectin could also prevent the growth and invasion of BC cells by activating AMPK and inhibiting PI3K/AKT signaling pathway [13]. Adiponectin has a crucial role in obesity-associated BC. As previously documented, Mauro et al. found that adiponectin played an inhibitory role in ER-negative $\mathrm{BC}$ cell growth and progression in vitro and in vivo [36]. In contrast, low adiponectin levels was similar to those circulating adiponectin in obese patients, which was a growth factor for ER-positive $\mathrm{BC}$ cells that stimulated $\mathrm{BC}$ growth and progression [36]. Given that the downregulation of adiponectin in CAAs was similar to the mammary adipocytes in obese patients, low levels of CAA-secreted adiponectin might stimulate $\mathrm{BC}$ progression. It was of great interest that the adiponectin-to-leptin ratio derived from adipocytes in obese patients was different from that in normal people. Theriau et al. indicated that the adiponectin-to-leptin ratio was lower in obese patients, forming a growing environment that induced MCF-7 BC cells to enter the cell cycle [37]. This result was consistent with other studies that a high leptin-to-adiponectin ratio was associated with an increased risk of progression in postmenopausal $\mathrm{BC}$ and triple-negative $\mathrm{BC}$ (TNBC) $[20,38]$. Hence, not only the increased adiponectin level but also the lower leptin-to-adiponectin ratio is associated with the decreased $\mathrm{BC}$ growth.

\section{II-6}

Under pathological conditions like obesity and cancer, the level of IL- 6 secreted by adipocytes is significantly 
increased. Among various cytokines secreted by adipocytes, the pleiotropic cytokine IL-6 is produced significantly, which is related to the development of stem cell phenotype, angiogenesis, cachexia, and resistance to therapy in BC [39]. IL-6 is identified as an independent adverse prognostic variable for overall survival and thereby is confirmed to be correlated with poor survival in hormone-refractory metastatic BC patients [40].

IL-6 expression is increased in CAAs and significantly boosts BC development. The study of Lee et al. showed that 3T3-L1 adipocytes indirectly co-cultivated with BC cells up-regulated the expression of inflammationrelated genes IL-6 and Ptx3, which was consistent with the IL-6 overexpression observed in CAAs of human BC tissues [41]. Likewise, the secretion of adipocyte-derived IL-6 was increased when adipocytes were cocultured with MDA-MB-231 BC cells in vitro, while IL-6 blocking significantly decreased both the size and number of nodules in lung metastasis model of BC [24]. Fujisaki et al. isolated normal breast adipocytes and CAAs, and cocultured them in collagen gels to mimic the in vivo environment, confirming the higher levels of IL- 6 in the CAA-conditioned medium [12]. Their results also confirmed that IL- 6 antibody neutralization abrogated the migration-enhancing effects of CAA-conditioned medium. Nickel et al. illustrated that after co-cultivation with adipocytes, migratory capacities were significantly increased in TNBC cells with the elevated secretion of IL-6, leading to an enhanced aggressive cell phenotype [42]. Adipocyte-derived IL-6 could also enhance the aggressive behavior of $\mathrm{BC}$ cells and induce EMTphenotype [43]. Blocking the IL-6 signal in BC cells and adipocytes reduced proliferation, migration, and invasion capabilities of $\mathrm{BC}$ cells by altering the expression of EMT-regulating genes, destabilizing the focal adhesion and reducing cell motility [44].

\section{CCL2 and CCL5}

CCL2 is encoded by the CCL2 gene which is located on chromosome 17q12. Through binding to the G-proteincoupled receptors CCR2, CCL2 is a chemoattractant for recruiting CCR2-expressing immune cells to the inflammatory region [45]. CCL2 has been proposed as a target for metastatic BC because the high expression of CCL2 is correlated with a decrease in the survival of $\mathrm{BC}$ patients [46]. A neutralization experiment using antibodies against IL-6 or CCL2 showed the abolishment of migration-enhancing effects of the CAA-conditioned medium [12]. The result indicated that adipocytes could revert to an immature and proliferative phenotype in the presence of $\mathrm{BC}$ cells, and can promote cell migration via adipokines including IL-6 and CCL2 [12]. Hsieh et al. also found that adipocyte-derived CCL2 production was increased by co-culturing with $4 \mathrm{~T} 1$ cells, and this phenomenon was broken by aspirin inhibition which might contribute to CCL2 chemo-preventive properties in BC [47]. Santander et al. reported that the expression of CCL2 was increased when E0771 BC cells were cocultured with adipocytes and macrophages, thus recruiting more monocytes/macrophages in tumor progression [48]. In particular, there is the possibility that CCL2 plays a key role in the cross-talk between adipocytes and $\mathrm{BC}$.

CCL5-CCR5 axis is related to the invasion and metastasis of BC. CCL5, initially termed as RANTES, is a potent chemokine that can attract leukocytes and a versatile inflammatory mediator expressed by $\mathrm{BC}$ cells [49]. Overexpression of CCL5 was correlated with ERK phosphorylation in tumor cells, and was statistically associated with poor disease-free survival and overall cancer survival in patients with early HER2-positive BC [50]. The abundance of CCL5 in peritumoral adipose tissues of TNBC patients is also correlated with metastasis and poor overall survival. Song et al. discovered that the elevated secretion of CCL5 in adipocytes co-cultured with TNBC cell lines heightened the EMT effect, thereby promoting the tumor growth, and lung and liver metastasis [51]. More importantly, another study showed that human adipocytes enhanced the invasiveness of MDA-MB231 cells, and the antagonism of CCL5 with specific peptides and antibodies might reduce the invasiveness [52]. Therefore, antagonizing the expression of CCL2 and/or CCL5 in peritumoral adipocytes might be a novel therapeutic target for inhibiting $\mathrm{BC}$ growth and metastasis.

\section{Other adipokines}

In addition to the adipokines mentioned above, there are exceptional multiple adipokines involved in the interaction between CAAs and $\mathrm{BC}$ cells, including resistin, insulin-like growth factor 1 (IGF-1), hepatocyte growth factor (HGF), platelet-derived growth factor-BB (PDGF$\mathrm{BB})$, insulin-like growth factor binding protein 2 (IGFBP-2), IL-1 $\beta$, IL-8, TNF- $\alpha$, granulocyte colonystimulating factor (G-CSF), vascular endothelial growth factor (VEGF) and autotaxin (ATX), lysophosphatidic acid (LPA). For example, resistin is an adipocytesecreted factor elevated in $\mathrm{BC}$ patients. Lee et al. found that resistin promoted $\mathrm{c}-\mathrm{Src}$ phosphorylation in $\mathrm{BC}$, while either inhibition of c-Src and PKC $\alpha$ or knockdown of ezrin could block resistin-induced BC cell invasion [53]. In addition, Xiong et al. differentiated bone marrow-derived monocytic progenitors into adipocytes and co-injected these adipocytes with E0771 BC cells subcutaneously into C57BL/6 mice [54]. They verified that among the adipocyte-secreted adipokines, IGF-1, HGF and PDGF-BB contributed to the proliferation and migration of $\mathrm{BC}$ cells. It was reported that the IGFBP-2 was secreted by mature adipocytes around metastatic breast tumors compared with that in non-metastatic 
tumor tissue, resulting in the promotion of metastatic ability of MCF-7 cells [55].

The study of Kolb et al. found that IL- $1 \beta$ from primary adipocytes induced ANGPTL4 expression in a manner dependent on NF- $\mathrm{kB}$ - and MAP kinase-activation, leading to increased angiogenesis and $\mathrm{BC}$ progression [56]. IL-8 is a clinically relevant and promising therapeutic target for treating human BC. IL-8 released by mammary adipocytes induced a pro-tumoral activation of neutrophils, mechanistically accompanied by the overexpression of cell-adhesion molecules, which further increased the dissemination capacity of BC cells [57]. IL-8 plays a critical role in the activation of CAAs and serves as a main mediator for the paracrine pro-carcinogenic effects of mammary adipocytes. Besides, Al-Khalaf et al. successfully isolated CAAs from 10 invasive breast carcinomas, and found that all CAAs secreted higher levels of IL-8, which was crucial for mediating paracrine procarcinogenic effects of CAAs and enhancing the proangiogenic effects [58]. G-CSF has been found to be elevated and associated with various cancer types by binding to G-CSFR. Liu confirmed that CAA-derived G-CSF was critical for the invasive ability of $\mathrm{BC}$, showing that targeting G-CSF/STAT3 signaling with G-CSF-neutralizing antibody could abrogate CAA-induced migration and invasion of $\mathrm{BC}$ cells [59]. In addition, co-culture of adipocytes and BC cells increased the secretion of VEGF and leptin, and thus enhanced the effects of estradiol and altered the risk of BC [60]. Co-cultured supernatants of adipocytes could also increase the proliferation, migration and sprouting of human umbilical vein endothelial cells (HUVECs), which might be ascribed to angiogenesisassociated VEGF [61]. Adipocytes, coupled with adiposederived stem cells (ADSCs), are the main producers of ATX and LPA, which have attracted much attention in $\mathrm{BC}$ development [62]. Bidirectional interactions between $\mathrm{BC}$ cells and mammary adipocytes altered the local LPA axis and increased ATX expression in the mammary fat pad during ER-negative BC progression [63]. Therefore, targeting the ATX-LPA axis may represent an additive cancer therapy for invasive and metastatic tumors depending on the BC subtype.

\section{Metabolic reprogramming}

Metabolic reprogramming, generally categorized as an emerging hallmark of cancer, is hijacked by $\mathrm{BC}$ to meet bioenergetic and biosynthetic demands, the redox balance maintenance, and cell proliferation [64]. The metabolic processes of $\mathrm{BC}$ and normal breast tissue are quite different in the aspect of glycolysis, tricarboxylic acid cycle, amino acids, nucleotides and/or lipid metabolism [65]. The nutrient transfer is an underlying mechanism in cancer-stromal cell crosstalk. Glutamine, the most abundant amino acid in the plasma, is the chief nutrient available to tumors, and is of great importance in tumor cell metabolism [66]. Recent studies have recognized that stromal cells could generate glutamine to promote cancer growth $[67,68]$. It has been reported that adipocytes secreted glutamine and rescued pancreatic cancer cell proliferation in the absence of glutamine in vitro, suggesting that glutamine transfer is a potential mechanism in adipocyte-induced pancreatic cancer cell proliferation [68]. Glutaminolysis enables cancer cells to reduce $\mathrm{NADP}^{+}$to NADPH, a reaction that is catalyzed by malic enzymes. Besides, NADPH is a required electron donor for reductive steps in lipid synthesis, nucleotide metabolism, and maintenance of reduced glutathione (GSH) [69]. CAAs play a functional role in tumor development through secreted adipocyte-derived factors and exosomes, and through metabolic symbiosis, in which malignant cells absorb lactic acid, fatty acids, and glutamine produced by adjacent adipocytes [70]. Therefore, it might be inferred that the metabolic reprogramming of glutaminolysis induced by CAAs could promote $\mathrm{BC}$ cells to regulate the redox state in order to favor proliferation.

Cancer cells prefer to produce adenosine triphosphate (ATP) by glycolysis, which is a less efficient pathway named as the "Warburg effect" compared to oxidative phosphorylation. The "reverse Warburg effect" is observed when cancer cells utilize the energy generated from stromal cells in the TME. In this theory, cancer cells can absorb free fatty acids (FFAs) and glycerol from interstitial adipocytes as energy sources $[8,71]$. Adipocytes store triglycerides through adipogenesis, and produce diacylglycerols, monoacylglycerols and FFAs through lipolysis, thus regulating the energy balance of the entire organism [72]. Cancer-associated fibroblasts (CAFs), which are the main cellular members of the TME undergo metabolic reprogramming associated with the reverse Warburg effect [69]. Cancer cells create a "pseudo-hypoxic" microenvironment for CAFs. As HIF- $1 \alpha$ promotes glycolysis and provides cancer cells with lactate and glutamate, increased reactive oxygen species (ROS) production in cancer cells induces the uptake of intermediate metabolites of the tricarboxylic acid (TCA) cycle in mitochondria indirectly. Cancer cell-derived ROS could down-regulate the expression of caveolin 1 (CAV1) in CAFs, and the loss of CAV1 also leads to increased ROS levels, thereby stabilizing HIF$1 \alpha$ [69]. The metabolic symbiosis between CAFs and epithelial cancer cells requires each other to express a different monocarboxylate transporter (MCT) isoform. MCT1 conduces to uptake the lactate produced by CAV1deficient CAFs expressing MCT4, a marker of aerobic glycolysis and lactate efflux. Cancer cells then utilize the lactate to synthesize pyruvate which is an intermediate metabolite in the TCA cycle, while the acidic extracellular space rich in lactate, in turn, results in the formation of pseudo-hypoxic [73]. A previous study indicated that 
adipocytes adjacent to $\mathrm{BC}$ cells underwent phenotypic changes first marked by decreased adipocyte size and lipid content (CAAs), next by acquiring a fibroblast-like morphology (adipocyte-derived fibroblasts, ADFs), still with small lipid droplets. Then, ADFs exhibited increased migratory and invasive abilities and were able to join the center of the tumor, and these cells no longer expressed adipose markers nor exhibited lipid droplets, indistinguishable from other CAFs cell population [74]. Moreover, in addition to that CAAs possess a similar functionality with CAFs, both CAAs and CAFs participate in the complex and dynamic metabolic reprogramming to shape the TME in favorable conditions.

The continuous interaction between $\mathrm{BC}$ and adipocytes results in metabolic competition and symbiosis, leading to oncogenic-driven metabolic reprogramming of cancer cells and neighboring adipocytes. FFAs could be released over time from lipid droplets through an adipose triglyceride lipase (ATGL) dependent lipolytic pathway. ATGL was expressed in human BC and was upregulated by the contact with adipocytes, thus boosting $\mathrm{BC}$ progression [75]. Through adipocyte-BC cell cocultivation, Balaban verified that adipocyte-derived FFAs transferred into $\mathrm{BC}$ cells and drove fatty acid metabolism via increased CPT1A and electron transport chain complex protein levels, resulted in fueling $\mathrm{BC}$ proliferation and migration [76]. Lipid originated from tumorsurrounding adipocytes could be transferred into BC cells. Utilization of adipocyte-derived lipids and enhanced intracellular trafficking of fatty acids contributed to $\mathrm{BC}$ progression, by increased expression of the key lipase ATGL and intracellular fatty acid trafficking protein fatty acid-binding protein 5 (FABP5) [77]. Tumor lipid metabolism is regulated not only by genetic and epigenetic changes in the tumor cells but also by the availability of lipids provided by tumor-surrounding adipocytes. Zaoui et al. showed that mammary adipocytes potentiated the invasiveness of $\mathrm{BC}$ cells and the number of lipid droplets in adipocyte cytoplasm, which were mediated by metabolic reprogramming via CD36-mediated exogenous fatty acid uptake [78]. Wang et al. reported the function of the JAK/STAT3 pathway in regulating lipid metabolism, once inhibiting JAK/STAT3 would lead to the block of diverse lipid metabolic gene expression, including CPT1B that encoded the critical enzyme for FAO [25]. Mammary adipocyte-derived leptin could also downregulate $\mathrm{CD}^{+} \mathrm{T}$ cell effector functions through activating STAT3-FAO and inhibiting glycolysis in promoting obesity-associated breast tumorigenesis [27].

In addition to $\mathrm{BC}$ cell reprogramming induced by CAAs, adipocytes also undergo reprogramming to become CAAs under the stimulation of BC cells in reverse. Cytokines or exosomal compositions (proteins, miRNAs, lncRNAs and circRNAs) are probably exploited by BC cells as a sort of "signal" to convert the cells in TME such as adipocytes and CAFs into a pro-tumor niche. For example, $\mathrm{Wu}$ et al. confirmed that exosomes containing miRNA-144 and miRNA-126 were highly secreted from BC cells co-cultured with adipocytes, leading to promoted metastasis by inducing beige/brown differentiation and reprogramming the metabolism in surrounding adipocytes in vivo [79]. They indicated a new mechanism that tumor-adipocyte interaction reprogramed systemic energy metabolism to facilitate tumor progression [79]. Lee et al. also confirmed the importance of miRNA-regulatory mechanisms of the transition into inflammatory CAAs in BC microenvironment [41]. In this study, mmu-miR-5112 showed the highest expression in the preadipocyte state and the expression was suppressed during the process of adipocyte differentiation. Mmu-miR-5112 mediated the regulation of IL-6 in CAAs, which presented de-differentiated and inflammatory natures in BC TME [41]. This miRNA-based regulatory mechanism involved acquiring the inflammatory phenotypes of CAAs. In addition, using specific shRNA, anti-IL-8 antibody, or reparixin, Al-Khalaf et al. found that the IL-8 signaling inhibition suppressed the active features of CAAs features, including non-cellautonomous tumor-promoting activities both on breast luminal cells and in orthotopic tumor xenografts in mice [58]. It provided a clear indication that IL-8 was a critical factor in the activation of breast CAAs. Wei et al. reported that plasminogen activator inhibitor type 1 (PAI$1)$, which had been implicated as a pro-tumorigenic agent in cancers, particularly in cancer metastasis, was required to activate the expression of the intracellular enzyme PLOD2 in CAAs [80]. Furthermore, PLOD2producing CAAs could remodel collagen alignment during crosstalk with $\mathrm{BC}$ cells and further promoted BC metastasis [80]. Therefore, these studies have indicated that there is a complex metabolic network favoring malignant progression that is established between $\mathrm{BC}$ cells and adipocytes at the tumor invasive front. The interaction entails a vicious circle, wherein BC cells reprogram adipocytes, which in turn promote tumor progression. Specific factors, such as inflammatory factors, IncRNAs, exosomal compositions and adrenomedullin, have been demonstrated to be involved in this process.

\section{Extracellular matrix remodeling}

Adipose tissue is surrounded by a basement membrane, which is mainly composed of collagen IV, laminin and fibronectin. Components released by adipocytes possess the capability of remodeling ECM and shaping the BC course [8]. ECM adaptation is essential for the progression and invasion of $\mathrm{BC}$, which could be possibly altered by adipocytes. Interestingly, in an accessible 3-dimensional (3D) 
co-culture system, Pallegar et al. demonstrated that adipocytes promoted a mesenchymal-to-epithelial transition (MET)-like change in mesenchymal TNBC cells, emphasizing the reciprocal interaction between high adiposity and $\mathrm{BC}$ metastasis with adipocyte abundance [81].

Adipocytes in $\mathrm{BC}$ can affect the synthesis of matrix proteins and the activation of matrix-related enzymes. Adipocytes can secrete multiple components orchestrating for ECM mechanical support. An immunostaining study of the clinical samples represented that the metastatic human BC tumors had higher levels of matrix metalloproteinase (MMP)-2, compared with non-metastatic tumor tissues; whereas adipocytes around metastatic BC tumors had higher levels of IGFBP-2 than that of nonmetastatic sites [55]. Furthermore, co-culture media of mature adipocytes and MCF-7 BC cells showed remarkably up-regulated MMP-2 and enhanced invasion ability of MCF-7 cells [55]. Juárez-Cruz et al. proved that adipocyte-derived leptin promoted the secretion of ECM remodelers, MMP-2 and MMP-9 in a FAK and Srcdependent manner, thereby degrading collagen IV and promoting the rupture of basement membranes [23]. The results suggested that leptin promoted $\mathrm{BC}$ into a more aggressive invasive phenotype. Furthermore, another study showed that MMP-2 and MMP-9 suppression could result in the inhibition of $\mathrm{BC}$ invasion via emodin by down-regulating the level of CCL5 from adipocytes. It was meaningful to antagonize the secretion of CCL5 from adipocytes for inhibiting BC metastasis. Similarly, adipocytes cultivated with cancer cells exhibited an altered phenotype including MMP-11 overexpression, and played a key role in the acquired proinvasive effect of tumor cells [14, 82].

Adipocytes also played a vital role in tumor growth at early stages through secretion and processing of collagen VI [83]. Collagen VI, a soluble ECM protein abundantly expressed in adipocytes and enriched in $\mathrm{BC}$ lesions, is a key protein for BC ECM. By secreting and processing collagen VI, adipocytes were essential in defining the ECM environment for normal and tumor-derived ductal epithelial cells and contributed significantly to tumor growth [83]. Park et al. investigated that endotrophin, which was derived from collagen VI cleaved by MMP11 , showed a strong stimulating effect on the growth, angiogenesis, and tissue fibrosis of $\mathrm{BC}$ [84]. Besides, endotrophin acted as a stimulator to promote the EMT through enhanced TGF- $\beta$ signaling, contributing to aggressive and high metastatic $\mathrm{BC}$ growth [84].

A collagen-dense ECM can potently interact with hormonal signals to drive invasion and metastasis of ERpositive BC [85]. PLOD2 participated in collagen synthesis. Accordingly, the research of $\mathrm{He}$ et al. clarified that adipocyte-derived IL-6 and leptin could promote PLOD2 expression by activating the JAK/STAT3, thus facilitating the hardness and metastasis of $\mathrm{BC}$ [24]. By constructing a 3D collagen invasion model, Wei et al. showed that CAAs remodeled collagen alignment concerning of PAI-1 or PLOD2 up-regulation during crosstalk with $\mathrm{BC}$ cells in vitro and in vivo, further boosting $\mathrm{BC}$ metastasis [80]. It is worth noting that the increased matrix stiffness, which can be sensed by many cell types, is a feature of most solid tumors [86]. Yes-associated protein (YAP) function is essential to establish and maintain the tumor-promoting function of CAFs, including stromal sclerosis, invasion and angiogenesis. The high level of YAP in the matrix is maintained by the positive feedback between CAF-driven matrix hardening and mechanical conduction, leading to YAP activation [87]. It has been reported that the Hippo pathway can be activated by stromal stiffness in solid tumor tissues, and central to this signaling is a kinase cascade leading from the tumor suppressor Hippo to the oncogenic Yki (YAP/TAZ in mammals), which is a transcriptional coactivator of target genes involved in cell proliferation and survival [88]. In addition, YAP is activated in CAFs in response to mechanical stress, perturbation of the actin cytoskeleton and ECM stiffness [86, 87]. Besides, the increased expression of YAP in preadipocytes is correlated with the repression of adipogenic differentiation processes [89]. Wang et al. conducted a transcriptomic analysis to find that mesenchymal stromal/stem cell (MSC)-differentiated adipocyte exosomes activated the Hippo signaling pathway involved in two key downstream Hippo proteins YAP and TAZ in MCF-7 cells, while the Hippo pathway blockade could lead to reduced tumor growth [90]. This result mechanistically emphasized that the Hippo signaling pathway was partially responsible for the tumor-promoting effects of MSC-differentiated adipocyte exosomes [90]. Therefore, YAP-dependent matrix stiffening driven by CAFs or YAP activation induced by adipocytes, might lead to pro-tumorigenic YAP activation in $\mathrm{BC}$ cells in close proximity to the stiff matrix.

Therefore, these studies demonstrate that adipocytederived factors exert roles in ECM architecture remodeling for facilitating the $\mathrm{BC}$ cell migration and motility. Abrogating CAA-dependent ECM re-organization of BC will decrease the directional migration of cancer cells within the matrices, thus leading to favorable outcomes.

\section{microRNAs}

miRNAs are a unique class of endogenous small, short single-stranded, and non-coding RNA molecules. The most important function of miRNAs is to negatively regulate numerous mRNAs by silencing their target transcripts. Accumulating evidence indicates that the expression of miRNAs during $\mathrm{BC}$ progression is aberrantly altered while several miRNAs are recognized to be crucial regulators of adipose microenvironment [91, 92]. Rajarajan et al. found that in vitro co-culture of $\mathrm{BC}$ cells 
with mature adipocytes increased proliferation, migration, and invasive phenotype of $\mathrm{BC}$ cells, and $98 \mathrm{miR}$ NAs were differentially expressed in BC cells by using small RNA-sequencing analysis [93]. Among them, miR3184-5p and miR-181c-3p were found to be the most up-regulated and down-regulated miRNAs, and direct targets were FOXP4 and PPAR $\alpha$, respectively. It was hypothesized by Lee et al. that mmu-miR-5112 treatedadipocytes showed up-regulation of IL-6 by targeting Cpeb1, proposing a miRNA-based regulatory mechanism underlying the process of acquiring inflammatory phenotypes in CAAs [41]. Wu et al. revealed that tumor cells co-cultivated with mature adipocytes exhibited an aggressive phenotype through inducing EMT, while BC cell-secreted miR-155 promoted beige/brown differentiation and remodeled metabolism in resident adipocytes [94]. Interactions between adipocytes and BC cells stimulated cytokine production and drove $\mathrm{src} / \mathrm{sox} 2 / \mathrm{mir}-$ 302b-mediated malignant progression [95]. Besides, miR-141 and miR-146b-5p were two important tumor suppressor miRNAs in $\mathrm{BC}$, and mediated the p16negative regulation of leptin in adipocytes [96]. In summary, miRNAs are key factors and mediators in intercellular communication. In the progress and metastasis of $\mathrm{BC}$, the miRNA-based regulatory mechanism is closely related to the adipocyte-secreted factors.

\section{Immune cells}

The peritumoral adipocytes induce an immune remodeling in favor of cancer aggressiveness and progression, mainly including cells of monocytes, macrophages, neutrophils and $\mathrm{T}$ cells [97, 98]. Crown-like structures (CLSs), composed of macrophages encapsulating dead or dying adipocytes, are a histologic hallmark of the proinflammatory process. In this process, adipose tissue contributes to the increased risk and worse prognosis of $\mathrm{BC}$ in obese, postmenopausal patients as well as some normal-weight women [99]. $\mathrm{CD}^{+} 8^{+}$and/or $\mathrm{CD} 163^{+}$ TAM infiltration, coupled with CLSs, is present in adipose tissue nearby the $\mathrm{BC}$ lesion, and is associated with various clinicopathologic parameters of $\mathrm{BC}$ [17]. Besides, the adipocyte-derived chemokines, such as CCL2, recruited macrophages to the TME and further triggered BC development $[48,84,100,101]$. In addition, adipokines are able to induce angiogenesis in driving tumor progression through macrophages. Several adipokines including leptin, IL-6, and TNF- $\alpha$ are capable of increasing VEGFA expression in THP-1 macrophages cocultured with adipocytes. Compared with THP-1 cells cultured alone, the medium of THP-1 cells previously exposed to human adipocytes stimulated endothelial tube formation more significantly [102]. Therefore, revealing the underlying mechanisms of adipocyte-driven immune cells and immune cascades is necessary to understand the role of adipokines in TME.

\section{Adipocytes in breast cancer therapy}

In addition to promoting $\mathrm{BC}$ aggressiveness, adipose secretome and cellular interactions are implicated in the resistance to multiple therapies, including chemotherapy, hormonal therapy, radiotherapy and immunotherapy. The known drug-resistant mechanisms mainly include activation of drug transporter proteins, evasion of therapy-induced apoptosis, enhanced DNA repair mechanisms and alterations of drug metabolism [103].

Indeed, adipose microenvironment has been described to influence the anti-cancer efficiency of chemo- and hormonal therapies (doxorubicin, tamoxifen and fulvestrant). Tumor-surrounding adipocyte-stimulated chemoresistance has been corroborated by lots of studies. Major vault protein (MVP) is a transport-associated protein with up-regulated expression in BC mediated by adipocytes. Cocultivation with human mammary adipocytes induced chemoresistance in $\mathrm{BC}$ cells, manifested as a result of altered subcellular distribution and excretion from the $\mathrm{BC}$ cell membrane treated with doxorubicin. The result was a piece of evidence that adipocytes induced an MVP-related multidrug-resistant phenotype, which could contribute to obesity-related chemoresistance [104]. Sequester and efficient metabolism of a pharmaceutical agent by adipocytes could be clinically important for adipocyte-riched cancer microenvironments such as omentum, breast, and marrow. Sheng et al. pointed out that adipocytes metabolized daunorubicin to a less toxic metabolite, and allowed nearby acute lymphoblastic leukemia cells to evade daunorubicin-induced cytotoxicity [105]. It is known that cancer stem cells (CSCs) are metabolically distinct from cancer cells and are critical for chemoresistance. Wang et al. found that the mammary adipocyte-derived leptin promoted cancer cell stemness, and thus enhanced the chemoresistance by activating STAT3-CPT1B-FAO in breast CSCs [25]. This study identified a critical strategy that blocking FAO and/or leptin re-sensitized the $\mathrm{BC}$ cells to chemotherapy. Besides, adipokines, such as leptin, were able to weaken the antitumor effect of hormonal tamoxifen therapy [106]. For instance, Bougaret et al. investigated that leptin, IL-6 and TNF- $\alpha$ in obese patients decreased the anti-proliferative efficacy of 4-hydroxytamoxifen, which was a major active metabolite of tamoxifen [107]. In overall and tamoxifentreated $\mathrm{BC}$ patients, leptin expression correlated with poor prognosis [108].

It is also of interest that the interactions between adipocytes and $\mathrm{BC}$ cells participate in the resistance of radiotherapy and immunotherapy. In a vitro assay, Bochet et al. showed that BC cells exhibited enhanced IL-6 expression, Chk1 phosphorylation, and a radioresistant phenotype in 
the presence of adipocytes, revealing a new role of tumorsurrounding adipocytes in fostering a radioresistant phenotype in BC [109]. Tang et al. reported that the mammary adipocyte-derived ATX secretion was promoted by BC-produced inflammatory cytokines, leading to enhanced resisting effects in radiotherapy or chemotherapy $[110,111]$. Thus, inhibiting adipocyte-derived ATX provided a promising adjuvant to improve $\mathrm{BC}$ outcomes of radiotherapy and chemotherapy.

Acquired resistance to trastuzumab is a clinical problem in the treatment of HER2-over-expressing metastatic BC. Adipocyte-secreted factors such as growth differentiation factor 15 (GDF15), resulted in reduced response to trastuzumab by stimulating PI3K signaling [112]. Duong et al. also proved that adipocytes could promote resistance of HER2-expressing $\mathrm{BC}$ cells to trastuzumab-mediated antibody-dependent cellular cytotoxicity, via reducing interferon (IFN)- $\gamma$ secretion by NK cells [113]. Besides, $\mathrm{Wu}$ et al. showed that adipocyte-secreted PD-L1 could prevent the anti-PD-L1 antibody from activating important antitumor functions of $\mathrm{CD}^{+} \mathrm{T}$ cells [114]. Hence, pharmacologic inhibition of adipogenesis selectively reduced PD-L1 expression in murine adipose tissue and enhanced the antitumor efficacy of anti-PD-L1 or anti-PD-1 antibodies in syngeneic mammary tumor models.

Collectively, it is important to underline the utility of adipokines as predictors for drug resistance and the role of adipose tissue in the resistance to $\mathrm{BC}$ therapy (Table 2). Approaches targeting the adipocyte and cancer cell crosstalk may help sensitize cancer cells to BC therapy, deserving further examined.

\section{Adipocytes in autologous fat grafting of breast reconstruction}

Autologous fat grafting is becoming an increasingly attractive procedure for breast reconstruction in $\mathrm{BC}$ patients who have undergone a mastectomy. The fat donor, harvested by liposuction, is transplanted into the breast to obtain a better breast morphology. Cellassisted lipotransfer (CAL) is a process in which fat grafting is supplemented with autologous ADSCs, and can reduce the fat absorption rate and improve the survival rate of fat grafting [115]. Regarding the contribution of CAAs to the progress of $\mathrm{BC}$, oncologic safety of breast lipofilling after a mastectomy is inevitably a major clinical issue. Even though the breast tumor of $\mathrm{BC}$ patients receiving fat grafting is removed, it still exists the possible presence of incipient in situ lesions or residual dormant tumor cells [13].

Previous studies have confirmed the role of adipocytes and ADSCs in promoting BC in a cell model and in vivo. In clinical studies, the risk of local recurrence in $\mathrm{BC}$ patients receiving autologous fat grafting after mastectomy remains in a twilight zone. Interestingly, Gebremeskel et al. reported that ADSCs fat grafting alone, but not conventional fat graft or cell-assisted lipotransfer, could promote $\mathrm{BC}$ cell proliferation and invasiveness in vitro and in mouse model [116]. The possible potential reasons were that the fat might act as a barrier to prevent ADSC-produced soluble factors from reaching cancer cells, and co-injected fat might exert a paracrine influence on ADSCs, causing them to preferentially undergo adipogenesis as opposed to angiogenesis. Cohen

Table 2 The impact of adipocytes on breast cancer therapy

\begin{tabular}{|c|c|c|c|c|}
\hline $\begin{array}{l}\text { Therapeutic } \\
\text { type }\end{array}$ & Therapeutic drug & Cancer cell type & Mechanism of therapeutic resistance & Ref. \\
\hline \multirow[t]{2}{*}{ Chemotherapy } & Doxorubicin & $\begin{array}{l}\text { T47D, MDA-MB453, BT-474, } \\
\text { MDA-MB436, MDA-MB231, } \\
\text { M-Wnt and E0771 }\end{array}$ & $\begin{array}{l}\text { Adipocytes induced an MVP-related DOX-resistant phenotype } \\
\text { in BC cells }\end{array}$ & [104] \\
\hline & Paclitaxel & MDA-MB-231 & $\begin{array}{l}\text { Mammary-adipocyte-derived leptin upregulated CPT1B expression } \\
\text { and FAO activity in BCSCs, thus promoting cancer cell stemness } \\
\text { and chemoresistance }\end{array}$ & [25] \\
\hline Hormonal therapy & Tamoxifen & $\begin{array}{l}\text { MCF-7, MDA-MB-231, T47D } \\
\text { and MDA-MB-435 }\end{array}$ & $\begin{array}{l}\text { Mature adipocytes and their secretions were able to increase } \\
\text { mammary cancer cell proliferation and to suppress the } \\
\text { antiproliferative effect of tamoxifen }\end{array}$ & [106-108] \\
\hline \multirow[t]{2}{*}{ Radiotherapy } & - & SUM159PT & $\begin{array}{l}\text { Tumor-surrounding adipocytes fostered a radioresistant phenotype } \\
\text { in breast tumors through the increasing expression of IL-6 in } \\
\text { tumor cells }\end{array}$ & [109] \\
\hline & - & $\mathrm{Hs578T}$ and $4 \mathrm{~T} 1$ & $\begin{array}{l}\text { Inflammatory cytokines produced by tumors increased ATX } \\
\text { secretion of mammary adipocytes, and enhanced the ATX-LPA } \\
\text { inflammatory cycle, thus resisting radiotherapy }\end{array}$ & {$[110,111]$} \\
\hline \multirow[t]{2}{*}{ Immunotherapy } & Trastuzumab & $\begin{array}{l}\text { BT-474, SK-BR-3, MDA-MB-453, } \\
\text { and MDA-MB-361 }\end{array}$ & $\begin{array}{l}\text { Adipocytes inhibited trastuzumab-mediated ADCC in } \\
\text { HER2-expressing BC cells via the secretion of soluble factors }\end{array}$ & [113] \\
\hline & $\begin{array}{l}\text { Anti-PD1/PD-L1 } \\
\text { antibody }\end{array}$ & E0771 & $\begin{array}{l}\text { Adipocyte PD-L1 prevented anti-PD-L1 antibody from activating } \\
\text { important antitumor functions of CD8 }{ }^{+} \mathrm{T} \text { cells }\end{array}$ & [114] \\
\hline
\end{tabular}

Abbreviations: $D O X$ doxorubicin; MVP major vault protein; $B C$ breast cancer; $B C S C$ s breast cancer stem cells; $C P T 1 B$ carnitine palmitoyltransferase $1 \mathrm{~B} ; F A O$ fatty acid $\beta$-oxidation; $A D C C$ antibody-dependent cellular cytotoxicity; HER2 human epidermal growth factor receptor 2 
et al. indicated that tumor recurrence rate in the autologous fat grafting group was $2.5 \%$, which was no significant difference with the control group, while the mean time to recurrence in the fat grafting group was significantly longer than that in the control group [117]. This provided valuable evidence-based support for oncologic safety of fat grafting. Similarly, in a case-controlled study involved in 205 patients with fat grafting reconstruction after BC surgery, the results showed that BC recurrence was not increased with lipofilling reconstruction [118].

Despite breast reconstruction using fat grafting is a standardized and widely popularized technique, evidence of oncological safety still deserves consideration. It is necessary to conduct clinical trials on a large scale and with long-term follow-up in order to ensure the oncologic safety of fat grafting after mastectomy. Besides, BC patients who needed autologous fat grafting should be strictly screened, and the potential recurrence should be closely observed after surgery. Patients with a high risk of $\mathrm{BC}$ recurrence should avoid or postpone autologous fat grafting and avoid injecting high purity ADSCs (Fig. 2).

\section{Conclusions}

Collectively, adipocytes are excellent candidates to modify tumor behavior through heterotypic signaling processes by the secretion of adipokines like hormones, growth factors, cytokines and other molecules. From the established evidence in vitro, in vivo and in clinical, it can be introduced as follows: (i) the characterization of factors derived from adipocytes is changed during tumor progression and is confirmed in human $\mathrm{BC}$ samples. (ii) $\mathrm{BC}$ cells remarkably impact on surrounding adipocytes; (iii) peritumoral adipocytes exhibit a modified phenotype and specific biological features sufficient to be named CAAs; and (iv) CAAs alter the BC cell characteristics/ phenotype leading to more aggressive behavior. Therefore, it can propose that adipocytes are the participators in a highly complex, inflammatory cycle orchestrated by $\mathrm{BC}$ cells to promote tumor progression which might be amplified in CAAs vicious function. Hereby, CAAs may become an obstacle to BC therapy. CAA-caused resistance in $\mathrm{BC}$ therapy, such as chemotherapy, radiotherapy, hormonal therapy and immunotherapy, might lead to persistent tumor residue and increased risk of recurrence.

Nevertheless, there are still some challenges in the identification for CAAs. At present, some CAA-related genes and protein markers have been identified but there is not a uniform certification standard of CAAs. Thus, CAA-related characteristics need to be further established. Significant effort based on CAAs should be invested to identify biomarkers for the diagnosis, prediction of therapy response, and prognosis of BC. The complicated mechanisms are involved in CAAs of $\mathrm{BC}$, including the secretion of adipokines, metabolic reprogramming, ECM remodeling, miRNAs and immune cells regulating. However, these potential mechanisms of CAAs remain largely elusive. For example, Ryu et al.

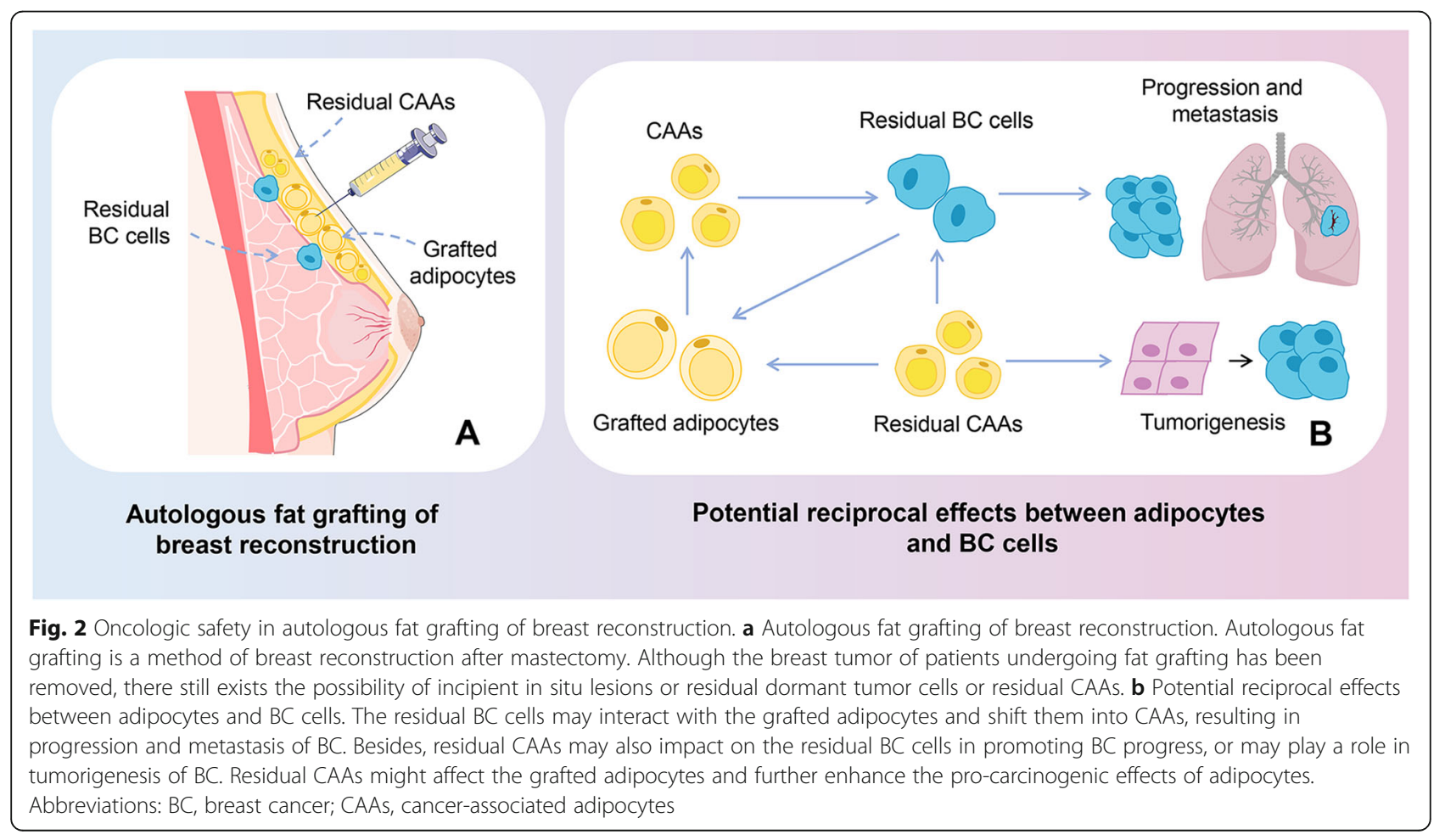


Table 3 The impact of CAAs on breast cancer subtypes

\begin{tabular}{|c|c|}
\hline Breast cancer subtype & Model \\
\hline ER-positive & Co-culture model (MCF-7) \\
\hline ER-negative & $\begin{array}{l}\text { Co-culture model (MDA- MB-231, MDA-MB- } \\
\text { 468) }\end{array}$ \\
\hline ER-positive & Co-culture model (MCF-7) \\
\hline ER-negative & Co-culture model (MDA-MB-231) \\
\hline ER-positive & Co-culture model (ZR 75.1) \\
\hline ER-negative & Co-culture model (SUM 159PT, 67NR, 4T1) \\
\hline Luminal A & $\begin{array}{l}\text { Co-culture model (MCF-7); human invasive } \\
\text { ductal carcinoma sample }\end{array}$ \\
\hline TNBC & $\begin{array}{l}\text { Co-culture model (MDA-MB-231); human } \\
\text { invasive ductal carcinoma sample }\end{array}$ \\
\hline TNBC & $\begin{array}{l}\text { Co-culture model (MDA-MB-231, MDA-MB- } \\
468) \text {; clinical samples in the dataset }\end{array}$ \\
\hline non-TNBC & $\begin{array}{l}\text { Co-culture model (SK-BR-3); clinical samples } \\
\text { in the dataset }\end{array}$ \\
\hline ER-positive & Co-culture model (MCF-7, ZR-75-1) \\
\hline ER-negative & Co-culture model (MDA-MB-231, Hs578T) \\
\hline
\end{tabular}

Not-given

ER-positive

TNBC

Luminal A

TNBC

TNBC

TNBC

ER-positive

Not-given

ER-positive

ER-negative
Human BC samples

Co-culture model (MCF-7, T47D)

Co-culture model (MDA-MB-231)

Co-culture model (MCF-7)

Co-culture mode (MDA-MB-468)

Co-culture model (MDA-MB-231, MDA-MB453)

Co-culture model (E0771); in vivo mouse orthotopic tumor model

Co-culture model (MCF-7)

10 metastatic pathologic samples and 10 non-metastatic pathologic samples

In vivo zebrafish model (MCF-7, T47D)

In vivo zebrafish model (MDA-MB-231)

\begin{tabular}{ll} 
Impact of CAAs on breast cancer subtypes & Ref. \\
\hline A direct co-culture between murine 3T3-L1-derived adi- & {$[11]$} \\
pocytes and BC cells of various molecular subtypes in- & \\
duced an EMT phenotype and enhanced their & \\
proliferation, migration, and invasion capabilities. &
\end{tabular}

CAA-conditioned medium increased the cell migration of both MCF-7 and MDA-MB-231 cells via IL-6 and CCL2.

Mature adipocytes were able to stimulate the invasive capacities of murine and human BC cell lines that are either positive (ZR 75.1) or negative (SUM159PT, 67NR, 4 T1) for the ER. Coculture with adipocytes had no effect on ZR 75.1, 67NR or 4T1 proliferation in contrast to SUM159PT cells.

A total of 1126 and 1218 proteins were identified in MCF-7 and MDA-MB-231 cells, respectively. Among these, 85 (MCF-7) and 63 (MDA-MB- 231) had an average fold change $>1.5$ following co-culture.

Adipocytes could facilitate the pro-metastasis role in TNBC and non-TNBC via PLOD2-dependent way. PLOD2 expression was much higher in TNBC patients, compared to non-TNBC patients.

The transition of adipocytes into more inflammatory CAAs resulted in proliferation-promoting effect in ERpositive BC cells such as MCF7 and ZR-75-1 but not in ER-negative cells; aromatase levels were upregulated in CAAs that might favor the growth of ER-positive BC cells.

The expression of IL-6 was up-regulated in CAAs in human $\mathrm{BC}$ tissues.

In ER-positive cell lines, top upregulated genes showed significant enrichment for hormone receptor target genes. In triple-negative MDA-MB-231 cells, co-culture with adipocytes led to the induction of pro-inflammatory genes, mainly involving genes of the Nf-kB signaling pathway, and increased secretion of the proinflammatory interleukins IL-6 and IL-8.

Human adipocytes could enhance proliferation, migration and invasion abilities of MDA-MB-468 and MCF-7 cells after co-culture, and these effects were more profound in MDA-MB-468 cells compared with MCF-7, which are non-invasive cells.

Elevated secretion of CCL5 in adipocytes co-cultured with the TNBC cell lines heightened the EMT effect, thereby promoting tumor growth and lung and liver metastasis.

Conditioned media from adipocytes supported E0771 cell proliferation and enhanced cell migration in vitro; adipocytes not only accelerated breast tumor growth, but also enhanced vascularization in vivo.

The co-culture media of human MCF-7 BC cells and human mature adipocytes increased the motility of MCF-7 cells through IGFBP-2.

Metastatic human breast tumors had higher levels of MMP-2 than did non-metastatic tumor tissue, whereas adipocytes around metastatic breast tumors had higher levels of IGFBP-2 than did adipocytes surrounding nonmetastatic breast tumors.

Breast adipocyte increased the dissemination of ERpositive BC cells in the zebrafish model of metastasis, while dissemination of the more aggressive and metastatic BC cells such as ER-negative was unaffected. 
Table 3 The impact of CAAs on breast cancer subtypes (Continued)

\begin{tabular}{|c|c|c|c|}
\hline Breast cancer subtype & Model & Impact of CAAs on breast cancer subtypes & Ref. \\
\hline Not-given & Human invasive ductal carcinoma sample & $\begin{array}{l}\text { CAAs isolated from } 10 \text { invasive breast carcinomas were } \\
\text { pro-inflammatory and exhibited active phenotypes, in- } \\
\text { cluding higher proliferative, invasive and migratory } \\
\text { capacities. }\end{array}$ & {$[58]$} \\
\hline TNBC & Co-culture model (MDA-MB-231, BT549) & \multirow{2}{*}{$\begin{array}{l}\text { CAAs could enhance migration and invasion of TNBC } \\
\text { cells, while the effect of CAAs on ER-positive BC cells } \\
\text { were limited. }\end{array}$} & \multirow[t]{3}{*}{ [59] } \\
\hline ER-positive & Co-culture model (MCF-7, T47D) & & \\
\hline Not-given & Human BC tissue sample & $\begin{array}{l}\text { Elevated G-CSF expression in adipocytes was well corre- } \\
\text { lated with activated Stat3 signal in cancer cells. }\end{array}$ & \\
\hline ER-negative & Co-culture model (M28N2, M27H4, M6) & $\begin{array}{l}\text { Mammary adipose tissue-derived lysophospholipids pro- } \\
\text { moted ER-negative mammary epithelial cell proliferation. }\end{array}$ & {$[63]$} \\
\hline Luminal A & Co-culture model (MCF-7) & \multirow{2}{*}{$\begin{array}{l}\text { Proliferation, migration and invasion were increased in } \\
\text { BC cells, which was most prominent for the highly } \\
\text { invasive SUM159 cells and, to a lesser extent, for the less } \\
\text { invasive MCF7 cells. }\end{array}$} & \multirow[t]{2}{*}{ [78] } \\
\hline TNBC & Co-culture model (SUM159) & & \\
\hline Not-given & Human invasive breast carcinoma sample & $\begin{array}{l}\text { Collagen reorganization at the tumor-adipose periphery, } \\
\text { as well as the positive relevance between PAI-1 and } \\
\text { PLOD2 were found in invasive breast carcinoma, reveal- } \\
\text { ing a new stromal collagen network that favors tumor in- } \\
\text { vasion and metastasis establish between BC cells and } \\
\text { surrounding adipocytes at the tumor invasive front. }\end{array}$ & {$[80]$} \\
\hline TNBC & Co-culture model (MDA-MB-231, Hs578t) & \multirow{2}{*}{$\begin{array}{l}\text { Adipocytes and adipocyte-derived conditioned media, } \\
\text { but not pre-adipocytes, caused the mesenchymal MDA- } \\
\text { MB- } 231 \text { and Hs578t cells to form significantly more } \\
\text { epithelial-like structures when compared to the typical } \\
\text { stellate colonies formed in control 3D cultures. MCF7 } \\
\text { cells had a less dramatic shift as they normally have a } \\
\text { more epithelial-like structure in 3D culture. }\end{array}$} & \multirow[t]{2}{*}{ [81] } \\
\hline Luminal A & Co-culture model (MCF7) & & \\
\hline ER-positive & Co-culture model (T47D) & \multirow{3}{*}{$\begin{array}{l}\text { Adipocytes caused DOX resistance in all the cell lines } \\
\text { studied, independently of the BC subtypes. }\end{array}$} & \multirow[t]{3}{*}{ [104] } \\
\hline HER2-positive & Co-culture model (MDA-MB453, BT-474) & & \\
\hline TNBC & $\begin{array}{l}\text { Co-culture model (MDA-MB436, MDA- } \\
\text { MB231, M-Wnt, E0771) }\end{array}$ & & \\
\hline
\end{tabular}

Abbreviations: $B C$ breast cancer; $E R$ estrogen receptor; TNBC triple-negative $B C ;$ IL-6 interleukin 6; IL-8 interleukin 8; CCL2 chemokine ligand 2; CCL5 chemokine ligand 5; CAAs cancer-associated adipocytes; EMT epithelial-mesenchymal transition; IGFBP-2 insulin-like growth factor binding protein 2; G-CSF granulocyte colony-stimulating factor; DOX doxorubicin; PLOD2 lysyl hydroxylase 2; PAl-1 plasminogen activator inhibitor type 1

concluded a contrary result in the prevailing concept of the cancer-promoting role of CAAs, presuming the interaction between $\mathrm{BC}$ and CAAs is rather complex [119]. Besides, some adipokines, like IL-6, are of paradoxical effect on promoting or inhibiting in different $\mathrm{BC}$ courses. Deciphering this complex network is critical to improving the treatment outcomes and the ultimate survival rate of patients.

Another important issue is the adipokine source in TME. Multiple cell types and soluble active factors comprise the intricate TME of $\mathrm{BC}$. It poses an issue that specific adipokines such as polyfunctional IL-6 could be released by different cell types, primary adipocytes, immune cells, or tumor cells. It would be an interesting angle that the specific factor is secreted by which cell type. Besides, the IL-6R is also expressed in these cell types, proposing the inclination of an autocrine or paracrine function. Although clinical specimens verified the correlation between certain CAA-factors and $\mathrm{BC}$, the tumor-promoting effect of CAAs is often determined by cell experiments in vitro, but not animals.

It will be meaningful to take consideration of CAA functions to the $\mathrm{BC}$ therapy tackled by researchers. The intervention between CAAs and $\mathrm{BC}$ cells might be a potential application in auxiliary therapy against $\mathrm{BC}$ development. It is noteworthy that the growth and metastasis characteristics of $\mathrm{BC}$ cells are closely related to $\mathrm{BC}$ subtypes. The existing studies on CAAs in BC mainly focus on $\mathrm{BC}$ subtypes as follows: ER-positive $\mathrm{BC}$, ER-negative $\mathrm{BC}, \mathrm{TNBC}$, non-TNBC, Luminal $\mathrm{A}$ and other unspecific $\mathrm{BC}$ subtypes (as described in Table 3). In all these BC subtypes, CAAs exhibit the ability to promote $\mathrm{BC}$ progress via their paracrine functions. CAAs are able to stimulate the migration and invasive capacities of ERpositive and negative $\mathrm{BC}$, and the promoting function seems to be more profound in ER-negative BC compared with ER-positive BC. In terms of the proliferationpromoting effect of CAAs, it is controversial to indicate 


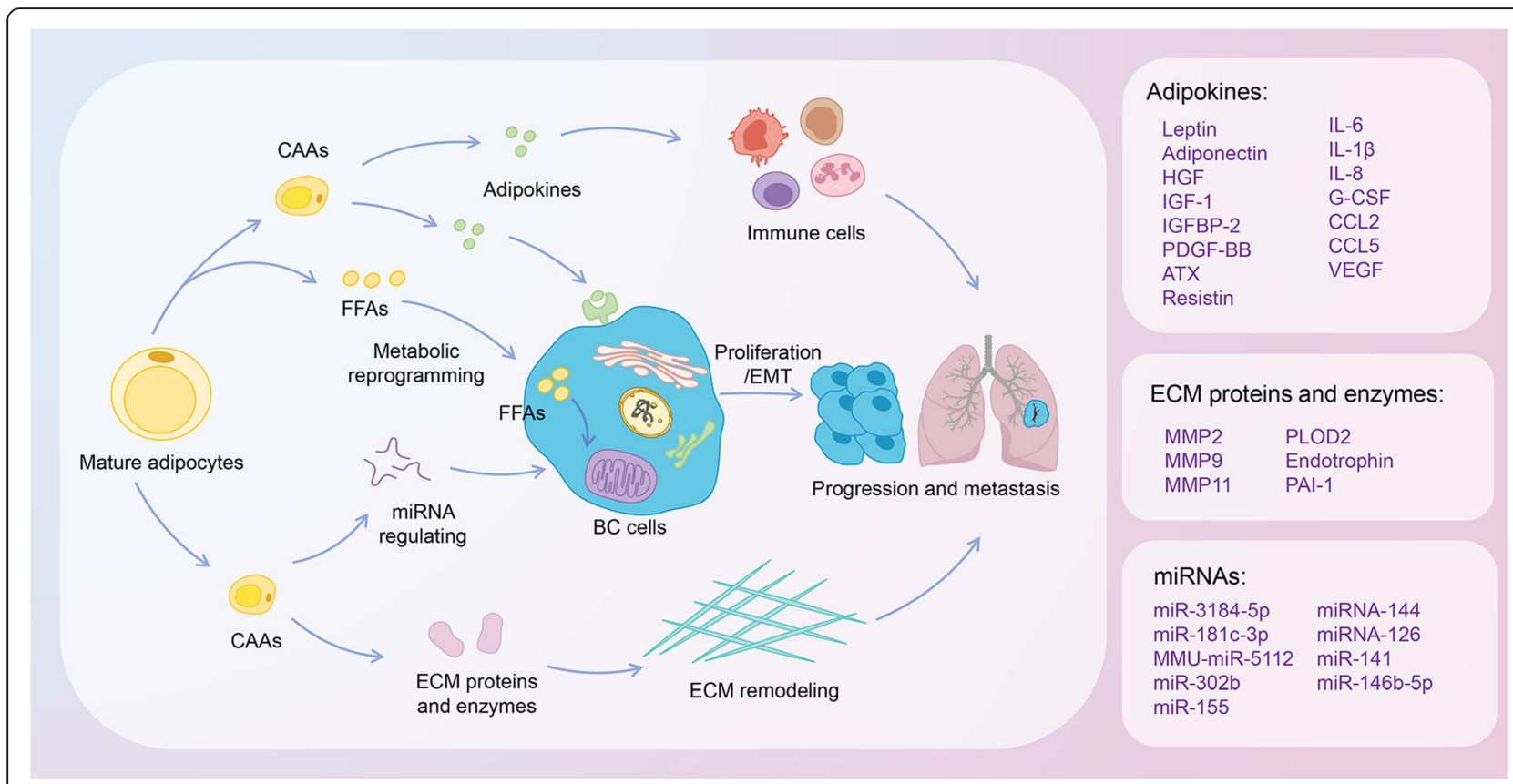

Fig. 3 Mechanisms of adipocytes in regulating the progression and metastasis of breast cancer. In invasive front of BC cells, adipocytes undergo lipolysis and change into an active phenotype, referred to as CAAs. CAAs are involved in the process of tumor progression and metastasis of BC, including secretion of multiple adipokines; ECM remodeling by expressing and activating of several ECM proteins and enzymes; metabolic reprogramming by transferring FFAs, released in the lipolysis process of adipocytes, into the BC cell and increasing FAO; miRNA regulating; immune cells. Abbreviations: BC, Breast cancer; CAAs, cancer-associated adipocytes; ECM, extracellular matrix; FFAs, free fatty acids; FAO, fatty acid $\beta$-oxidation; EMT, epithelial-mesenchymal transition

whether ER-negative BC or ER-positive BC is more obvious. Especially, TNBC accounts for nearly $15 \%$ of all invasive $\mathrm{BC}$, and possesses the highest rate of metastatic occurrence and the poorest overall survival in all $\mathrm{BC}$ subtypes. CAAs could change TNBC cells into more aggressive phenotypes with the enhanced ability of migration and invasion. Further studies are still needed to deeply uncover the underlying mechanisms of CAAs for a better comparison of different BC subtypes. The $\mathrm{BC}$ subtype together with different tumor processes would exert a certain impact on CAA-targeted therapy. Implementing other strategies designed to target the adipokine receptors might be beneficial to modulate the sensitivities of CAA-derived adipokines in reducing the prooncogenic function of CAAs, especially for metastasis. In particular, residual adipose tissue around BC tumor does make sense on the influence of recurrence after mastectomy, further affirming the clinical value of the precise resection boundary of adipose tissue. In addition, fat grafting may complicate breast imaging and BC surveillance because of fat necrosis and calcification in breast tissue. It is even more remarkable for plastic surgeons that whether the CAA-containing residual adipose tissue could lead to BC recurrence, and whether the residual CAAs could affect the grafted adipocytes in the process above.
Thus, we offer the key insights into the potential functions and mechanisms of CAAs in the $\mathrm{BC}$ microenvironment, proposing the possibility of anti-CAAs auxiliary therapy against BC development (Fig. 3). Further studies are required to investigate the CAA-associated strategy for better clinical outcomes of BC.

\section{Abbreviations}

BC: Breast cancer; CAAs: Cancer-associated adipocytes; TME: Tumor microenvironment; ECM: Extracellular matrix; miRNAs: microRNAs; WAT: White adipocytes; IL: Interleukin; CCL2: Chemokine ligand 2; CCL5: Chemokine ligand 5; EMT: Epithelial-mesenchymal transition; PKM2: Pyruvate kinase M2; FAK: Focal adhesion kinase; PLOD2: Lysyl hydroxylase 2; FAO: Fatty acid $\beta$-oxidation; TAMs: Tumor-associated macrophages; MT: Mammary tumor; TNF: Tumor necrosis factor; TGF: Transforming growth factor; HIF: Hypoxia-inducible factor; AMPK: AMPactivated protein kinase; mTOR: Mammalian target of rapamycin; mTORC1: mTOR complex 1; TSC2: Tuberous sclerosis 2; Raptor: Regulatoryassociated protein of mTOR; TNBC: Triple-negative BC; IGF-1: Insulin-like growth factor 1; HGF: Hepatocyte growth factor; PDGF-BB: Platelet-derived growth factor-BB; IGFBP-2: Insulin-like growth factor binding protein 2; GCSF: Granulocyte colony-stimulating factor; VEGF: Vascular endothelial growth factor; ATX: Autotaxin; LPA: Lysophosphatidic acid; HUVECs: Human umbilical vein endothelial cells; ADSCs: Adipose-derived stem cells; GSH: Glutathione; FFAs: Free fatty acids; ATP: Adenosine triphosphate; CAFs: Cancer-associated fibroblasts; ROS: Reactive oxygen species;

TCA: Tricarboxylic acid; CAV1: Caveolin 1; MCT: Monocarboxylate transporter; ADFs: Adipocyte-derived fibroblasts; ATGL: Adipose triglyceride lipase; FABP5: Fatty acid-binding protein 5; 3D: 3-dimensional; MET: Mesenchymalto-epithelial transition; MMP: Matrix metalloproteinase; PAI-1: Plasminogen activator inhibitor type 1; YAP: Yes-associated protein; MSC: Mesenchymal stromal/stem cell; CLSs: Crown-like structures; MVP: Major vault protein; 
CSCs: Cancer stem cells; GDF15: Growth differentiation factor 15; IFN: Interferon; CAL: Cell-assisted lipotransfer

\section{Acknowledgements}

Not Applicable.

\section{Authors' contributions}

Chongru Zhao, Min Wu and Ning Zeng performed literature searched and wrote the manuscript. Qi Zhang and Yiping Wu conceived the project and revised the manuscript. Mingchen Xiong, Weijie Hu, Wenchang Lv and Yi Yi edited the manuscript. All the authors reviewed the manuscript and all approved of the final version.

\section{Funding}

This work was supported by China GuangHua Science and Technology Foundation (grant number 2019JZXM001).

\section{Availability of data and materials}

Not Applicable.

\section{Ethics approval and consent to participate} Not Applicable.

\section{Consent for publication}

Not Applicable.

\section{Competing interests}

The authors declare no conflict of interest.

\section{Received: 11 June 2020 Accepted: 4 August 2020}

Published online: 12 August 2020

\section{References}

1. Bray F, Ferlay J, Soerjomataram I, et al. Global cancer statistics 2018: GLOBOCAN estimates of incidence and mortality worldwide for 36 cancers in 185 countries. CA Cancer J Clin. 2018;68(6):394-424.

2. Ponnusamy L, Natarajan SR, Thangaraj K, Manoharan R. Therapeutic aspects of AMPK in breast cancer: Progress, challenges, and future directions. Biochim. Biophys. Acta - Rev. Cancer. 2020;1874(1):188379.

3. Scheja L, Heeren J. The endocrine function of adipose tissues in health and cardiometabolic disease. Nat Rev Endocrinol. 2019;15(9):507-24.

4. Garcia-Estevez L, Moreno-Bueno G. Updating the role of obesity and cholesterol in breast cancer. Breast Cancer Res. 2019;21(1):35.

5. Wu Q, Li B, Li Z, et al. Cancer-associated adipocytes: key players in breast cancer progression. J Hematol Oncol. 2019;12(1):95.

6. Fletcher SJ, Sacca PA, Pistone-Creydt M, et al. Human breast adipose tissue: characterization of factors that change during tumor progression in human breast cancer. J Exp Clin Cancer Res. 2017;36(1):26.

7. Cha YJ, Koo JS. Adipokines as therapeutic targets in breast cancer treatment. Expert Opin Ther Targets. 2018;22(11):941-53.

8. Pallegar NK, Christian SL. Adipocytes in the Tumour Microenvironment. In: Siemann DW, editor. Tumor Microenviront. Chichester: Wiley; 2020. p. 1-13.

9. Tumminia A, Vinciguerra F, Parisi M, et al. Adipose tissue, obesity and Adiponectin: role in endocrine Cancer risk. Int J Mol Sci. 2019;20(12):2863.

10. Rybinska I, Agresti R, Trapani A, et al. Adipocytes in breast Cancer, the thick and the thin. Cells. 2020;9(3):560.

11. Lee YK, Jung WH, Koo JS. Adipocytes can induce epithelial-mesenchymal transition in breast cancer cells. Breast Cancer Res Treat. 2015;153(2):323-35.

12. Fujisaki $K$, Fujimoto $H$, Sangai $T$, et al. Cancer-mediated adipose reversion promotes cancer cell migration via IL-6 and MCP-1. Breast Cancer Res Treat. 2015;150(2):255-63.

13. Choi J, Cha YJ, Koo JS. Adipocyte biology in breast cancer: from silent bystander to active facilitator. Prog Lipid Res. 2018;69(August 2017):11-20.

14. Dirat B, Bochet $L$, Dabek $M$, et al. Cancer-associated adipocytes exhibit an activated phenotype and contribute to breast Cancer invasion. Cancer Res. 2011;71(7):2455-65.

15. Suárez-Nájera LE, Chanona-Pérez JJ, Valdivia-Flores A, et al. Morphometric study of adipocytes on breast cancer by means of photonic microscopy and image analysis. Microsc Res Tech. 2018;81(2):240-9.
16. Crake RLI, Phillips E, Kleffmann T, Currie MJ. Co-culture with human breast adipocytes differentially regulates protein abundance in breast Cancer cells. CANCER GENOMICS PROTEOMICS. 2019;16(5):319-32.

17. Cha YJ, Kim E-S, Koo JS. Tumor-associated macrophages and crown-like structures in adipose tissue in breast cancer. Breast Cancer Res Treat. 2018; 170(1):15-25.

18. Sánchez-Jiménez F, Pérez-Pérez A, de la Cruz-Merino L, Sánchez-Margalet V. Obesity and breast Cancer: role of Leptin. Front Oncol. 2019;9(July):1-12.

19. Pan H, Deng L-L, Cui J-Q, et al. Association between serum leptin levels and breast cancer risk. Medicine (Baltimore). 2018;97(27):e11345.

20. Sultana R, Kataki AC, Borthakur BB, et al. Imbalance in leptin-adiponectin levels and leptin receptor expression as chief contributors to triple negative breast cancer progression in Northeast India. Gene. 2017;621:51-8.

21. Gnerlich JL, Yao KA, Fitchev PS, et al. Peritumoral expression of Adipokines and fatty acids in breast Cancer. Ann Surg Oncol. 2013;20(S3):731-8.

22. Wei L, Li K, Pang $X$, et al. Leptin promotes epithelial-mesenchymal transition of breast cancer via the upregulation of pyruvate kinase M2. J Exp Clin Cancer Res. 2016;35(1):166

23. Juárez-Cruz JC, Zuñiga-Eulogio MD, Olea-Flores $M$, et al. Leptin induces cell migration and invasion in a FAK-Src-dependent manner in breast cancer cells. Endocr Connect. 2019:8(11):1539-52.

24. He J, Wei X, Li S-J, et al. Adipocyte-derived IL-6 and leptin promote breast Cancer metastasis via upregulation of Lysyl Hydroxylase-2 expression. Cell Commun. Signal. 2018;16(1):100.

25. Wang T, Fahrmann JF, Lee $H$, et al. JAK/STAT3-Regulated Fatty Acid $\beta$ Oxidation Is Critical for Breast Cancer Stem Cell Self-Renewal and Chemoresistance. Cell Metab. 2018;27(1):136-50 e5.

26. Li K, Wei L, Huang Y, et al. Leptin promotes breast cancer cell migration and invasion via IL-18 expression and secretion. Int J Oncol. 2016;48(6):2479-87.

27. Zhang C, Yue C, Herrmann A, et al. STAT3 Activation-Induced Fatty Acid Oxidation in CD8 ${ }^{+}$T Effector Cells Is Critical for Obesity-Promoted Breast Tumor Growth. Cell Metab. 2020;31(1):148-61 e5.

28. Maroni P. Leptin, Adiponectin, and Sam68 in bone metastasis from breast Cancer. Int J Mol Sci. 2020;21(3):1051.

29. Tuna BG, Cleary M, Dogan S. Roles of Adiponectin signaling related proteins in mammary tumor development. South Clin Istanbul Eurasia. 2019:30(4): 290-5.

30. Chung SJ, Nagaraju GP, Nagalingam A, et al. ADIPOQ/adiponectin induces cytotoxic autophagy in breast cancer cells through STK11/LKB1-mediated activation of the AMPK-ULK1 axis. Autophagy. 2017;13(8):1386-403.

31. Wu Q, Li B, Sun S, Sun S. Unraveling adipocytes and Cancer links: is there a role for senescence? Front Cell Dev Biol. 2020;8(April):1-7.

32. Hardie DG. AMP-activated/SNF1 protein kinases: conserved guardians of cellular energy. Nat Rev Mol Cell Biol. 2007:8(10):774-85.

33. Kim J, Kundu M, Viollet B, Guan KL. AMPK and mTOR regulate autophagy through direct phosphorylation of Ulk1. Nat Cell Biol. 2011; 13(2):132-41.

34. Hardie DG, Ross FA, Hawley SA. AMPK: a nutrient and energy sensor that maintains energy homeostasis. Nat Rev Mol Cell Biol. 2012;13(4):251-62.

35. Yoshida GJ. Therapeutic strategies of drug repositioning targeting autophagy to induce cancer cell death: from pathophysiology to treatment. J Hematol Oncol. 2017;10(1):1-14

36. Mauro L, Naimo GD, Gelsomino L, et al. Uncoupling effects of estrogen receptor a on LKB1/AMPK interaction upon adiponectin exposure in breast cancer. FASEB J. 2018;32(8):4343-55.

37. Theriau CF, Sauvé OS, Beaudoin M-S, et al. Proliferative endocrine effects of adipose tissue from obese animals on MCF7 cells are ameliorated by resveratrol supplementation. PLoS One. 2017;12(9):e0183897.

38. Ollberding NJ, Kim Y, Shvetsov YB, et al. Prediagnostic Leptin, Adiponectin, C-reactive protein, and the risk of postmenopausal breast Cancer. Cancer Prev Res. 2013;6(3):188-95

39. Gyamfi J, Eom M, Koo J-S, Choi J. Multifaceted roles of Interleukin-6 in adipocyte-breast Cancer cell interaction. Transl Oncol. 2018;11(2): 275-85.

40. Bachelot T, Ray-Coquard I, Menetrier-Caux C, et al. Prognostic value of serum levels of interleukin 6 and of serum and plasma levels of vascular endothelial growth factor in hormone-refractory metastatic breast cancer patients. Br J Cancer. 2003:88(11):1721-6.

41. Lee J, Hong BS, Ryu HS, et al. Transition into inflammatory cancer-associated adipocytes in breast cancer microenvironment requires microRNA regulatory mechanism. PLoS One. 2017;12(3):e0174126. 
42. Nickel A, Blücher $\mathrm{C}, \mathrm{Al} \mathrm{KO}$, et al. Adipocytes induce distinct gene expression profiles in mammary tumor cells and enhance inflammatory signaling in invasive breast cancer cells. Sci. Rep. 2018;8(1):9482.

43. Gyamfi J, Lee $Y-H$, Eom M, Choi J. Interleukin-6/STAT3 signalling regulates adipocyte induced epithelial-mesenchymal transition in breast cancer cells. Sci Rep. 2018;8(1):8859

44. Gyamfi J, Lee Y-H, Min BS, Choi J. Niclosamide reverses adipocyte induced epithelial-mesenchymal transition in breast cancer cells via suppression of the interleukin-6/STAT3 signalling axis. Sci Rep. 2019;9(1):11336.

45. Yoshimura T. The chemokine MCP-1 (CCL2) in the host interaction with cancer: a foe or ally? Cell Mol Immunol. 2018;15(4):335-45.

46. Bonapace L, Coissieux M-M, Wyckoff J, et al. Cessation of CCL2 inhibition accelerates breast cancer metastasis by promoting angiogenesis. Nature. 2014;515(7525):130-3.

47. Hsieh C-C, Huang Y-S. Aspirin breaks the crosstalk between 3T3-L1 adipocytes and $4 \mathrm{~T} 1$ breast Cancer cells by regulating cytokine production. PLoS One. 2016;11(1):e0147161.

48. Santander A, Lopez-Ocejo O, Casas O, et al. Paracrine interactions between adipocytes and tumor cells recruit and modify macrophages to the mammary tumor microenvironment: the role of obesity and inflammation in breast adipose tissue. Cancers (Basel). 2015;7(1):143-78.

49. Kranjc MK, Novak M, Pestell RG, Lah TT. Cytokine CCL5 and receptor CCR5 axis in glioblastoma multiforme. Radiol Oncol. 2019;53(4):397-406.

50. Zazo S, González-Alonso P, Martin-Aparicio E, et al. Autocrine CCL5 effect mediates trastuzumab resistance by ERK pathway activation in HER2positive breast cancer. Mol. Cancer Ther. 2020;molcanther.1172:2019.

51. Song X, Zhou X, Qin Y, et al. Emodin inhibits epithelial-mesenchymal transition and metastasis of triple negative breast cancer via antagonism of CC-chemokine ligand5 secreted from adipocytes. Int J Mol Med. 2018;42(1):579-88.

52. D'Esposito V, Liguoro D, Ambrosio MR, et al. Adipose microenvironment promotes triple negative breast cancer cell invasiveness and dissemination by producing CCL5. Oncotarget. 2016;7(17):24495-509.

53. Lee JO, Kim N, Lee HJ, et al. Resistin, a fat-derived secretory factor, promotes metastasis of MDA-MB-231 human breast cancer cells through ERM activation. Sci Rep. 2016;6(1):18923.

54. X Y. Hematopoietic Stem Cell-derived Adipocytes Promote Tumor Growth and Cancer Cell Migration. Int J Cancer Res Mol Mech. 2017;3(1):139-48.

55. Wang C, Gao C, Meng K, et al. Human adipocytes stimulate invasion of breast Cancer MCF-7 cells by secreting IGFBP-2. PLoS One. 2015;10(3): e0119348.

56. Kolb R, Kluz P, Tan ZW, et al. Obesity-associated inflammation promotes angiogenesis and breast cancer via angiopoietin-like 4. Oncogene. 2019; 38(13):2351-63.

57. Vazquez Rodriguez G, Abrahamsson A, Jensen LDE, Dabrosin C. Adipocytes promote early steps of breast Cancer cell dissemination via Interleukin-8. Front Immunol. 2018;9(July):1767.

58. Al-Khalaf HH, Al-Harbi B, Al-Sayed A, et al. Interleukin-8 activates breast Cancer-associated adipocytes and promotes their angiogenesis- and tumorigenesis-promoting effects. Mol Cell Biol. 2018. https://doi.org/10. 1128/MCB.00332-18

59. Liu L, Wu Y, Zhang C, et al. Cancer-associated adipocytes-derived G-CSF promotes breast cancer malignancy via Stat3 signaling. J Mol Cell Biol. 2020. https://doi.org/10.1093/jmcb/mjaa016

60. Morad V, Abrahamsson A, Kjölhede P, Dabrosin C. Adipokines and vascular endothelial growth factor in Normal human breast tissue in vivo correlations and attenuation by dietary flaxseed. J Mammary Gland Biol Neoplasia. 2016;21(1-2):69-76.

61. Bougaret $L$, Delort $L$, Billard $H$, et al. Supernatants of adipocytes from obese versus Normal weight women and breast Cancer cells: in vitro impact on angiogenesis. J Cell Physiol. 2017;232(7):1808-16

62. Schmid R, Wolf K, Robering JW, et al. ADSCs and adipocytes are the main producers in the autotaxin-lysophosphatidic acid axis of breast cancer and healthy mammary tissue in vitro. BMC Cancer. 2018;18(1):1273.

63. Volden PA, Skor MN, Johnson MB, et al. Mammary adipose tissue-derived Lysophospholipids promote estrogen receptor-negative mammary epithelial cell proliferation. Cancer Prev Res. 2016;9(5):367-78.

64. Sun $X$, Wang $M$, Wang $M$, et al. Metabolic reprogramming in triple-negative breast Cancer. Front Oncol. 2020. https://doi.org/10.3389/fonc.2020.00428.

65. Attane C, Milhas D, Hoy AJ, Muller C. Metabolic remodeling induced by adipocytes: a new Achille heels in invasive breast cancer? Curr Med Chem. 2018;25:1-15.
66. Deberardinis RJ, Cheng T. Q's next: the diverse functions of glutamine in metabolism, cell biology and cancer. Oncogene. 2010;29(3):313-24.

67. Yang $L$, Achreja A, Yeung $T$, et al. Targeting stromal glutamine Synthetase in tumors disrupts tumor microenvironment-regulated Cancer cell growth. Cell Metab. 2016;24(5):685-700.

68. Meyer KA, Neeley CK, Baker NA, et al. Adipocytes promote pancreatic cancer cell proliferation via glutamine transfer. Biochem Biophys Reports. 2016;7: 144-9.

69. Yoshida GJ. Metabolic reprogramming: the emerging concept and associated therapeutic strategies. J Exp Clin Cancer Res. 2015;34(1):1-10.

70. Munteanu R, Onaciu A, Moldovan C, et al. Adipocyte-based cell therapy in oncology: the role of cancer-associated adipocytes and their reinterpretation as delivery platforms. Pharmaceutics. 2020;12(5):1-32.

71. Dias AS, Almeida CR, Helguero LA, Duarte IF. Metabolic crosstalk in the breast cancer microenvironment. Eur J Cancer. 2019:121:154-71.

72. Grigoraş A, Amalinei C, Balan RA, et al. Adipocytes spectrum — from homeostasia to obesity and its associated pathology. Ann Anat - Anat Anzeiger. 2018;219:102-20.

73. Yoshida GJ, Azuma A, Miura Y, Orimo A. Activated fibroblast program orchestrates tumor initiation and progression; molecular mechanisms and the associated therapeutic strategies. Int J Mol Sci. 2019;20(9): 2256.

74. Bochet L, Lehuédé C, Dauvillier S. Adipocyte-Derived Fibroblasts Promote Tumor Progression and Contribute to the Desmoplastic Reaction in Breast Cancer; 2013. p. 5657-68.

75. Wang YY, Attané C, Milhas D, et al. Mammary adipocytes stimulate breast cancer invasion through metabolic remodeling of tumor cells. JCl Insight. 2017;2(4):e87489.

76. Balaban S, Shearer RF, Lee LS, et al. Adipocyte lipolysis links obesity to breast cancer growth: adipocyte-derived fatty acids drive breast cancer cell proliferation and migration. Cancer Metab. 2017;5(1):1.

77. Yang D, Li Y, Xing L, et al. Utilization of adipocyte-derived lipids and enhanced intracellular trafficking of fatty acids contribute to breast cancer progression. Cell Commun. Signal. 2018;16(1):32.

78. Zaoui M, Morel M, Ferrand N, et al. Breast-associated adipocytes Secretome induce fatty acid uptake and invasiveness in breast Cancer cells via CD36 independently of body mass index, menopausal status and mammary density. Cancers (Basel). 2019;11(12):2012.

79. Wu Q, Li J, Li Z, et al. Exosomes from the tumour-adipocyte interplay stimulate beige/brown differentiation and reprogram metabolism in stromal adipocytes to promote tumour progression. J Exp Clin Cancer Res. 2019; 38(1):223.

80. Wei X, Li S, He J, et al. Tumor-secreted PAl-1 promotes breast cancer metastasis via the induction of adipocyte-derived collagen remodeling. Cell Commun Signal. 2019;17(1):58

81. Pallegar NK, Garland CJ, Mahendralingam M, et al. A novel 3-dimensional co-culture method reveals a partial Mesenchymal to epithelial transition in breast Cancer cells induced by adipocytes. J Mammary Gland Biol Neoplasia. 2019:24(1):85-97.

82. Andarawewa KL, Motrescu ER, Chenard M-P, et al. Stromelysin-3 is a potent negative regulator of Adipogenesis participating to Cancer cell-adipocyte interaction/crosstalk at the tumor invasive front. Cancer Res. 2005;65(23): 10862-71.

83. lyengar $P$, Espina V, Williams TW, et al. Adipocyte-derived collagen VI affects early mammary tumor progression in vivo, demonstrating a critical interaction in the tumor/stroma microenvironment. J Clin Invest. 2005; 115(5):1163-76.

84. Park J, Scherer PE. Adipocyte-derived endotrophin promotes malignant tumor progression. J Clin Invest. 2012;122(11):4243-56.

85. Barcus CE, O'Leary KA, Brockman JL, et al. Elevated collagen-I augments tumor progressive signals, intravasation and metastasis of prolactin-induced estrogen receptor alpha positive mammary tumor cells. Breast Cancer Res. 2017;19(1):9.

86. Yoshida GJ. Regulation of heterogeneous cancer-associated fibroblasts: the molecular pathology of activated signaling pathways. J Exp Clin Cancer Res. 2020;39(1):112.

87. Calvo F, Ege N, Grande-Garcia A, et al. Mechanotransduction and YAPdependent matrix remodelling is required for the generation and maintenance of cancer-associated fibroblasts. Nat Cell Biol. 2013;15(6):637-46.

88. Zanconato F, Battilana G, Cordenonsi M, Piccolo S. YAP/TAZ as therapeutic targets in cancer. Curr Opin Pharmacol. 2016;29:26-33. 
89. Liu X, Long X, Gao Y, et al. Type I collagen inhibits adipogenic differentiation via YAP activation in vitro. J Cell Physiol. 2020;235(2):1821-37.

90. Wang S, Su X, Xu M, et al. Exosomes secreted by mesenchymal stromal/ stem cell-derived adipocytes promote breast cancer cell growth via activation of hippo signaling pathway. Stem Cell Res Ther. 2019;10(1):1-12

91. Halvorsen $A R$, Helland $\AA$, Gromov $P$, et al. Profiling of microRNAs in tumor interstitial fluid of breast tumors - a novel resource to identify biomarkers for prognostic classification and detection of cancer. Mol Oncol. 2017;11(2): 220-34.

92. Bandini E, Rossi T, Gallerani G, Fabbri F. Adipocytes and microRNAs crosstalk: a key tile in the mosaic of breast Cancer microenvironment. Cancers (Basel). 2019;11(10):1451.

93. Rajarajan D, Selvarajan S, Charan Raja MR, et al. Genome-wide analysis reveals miR-3184-5p and miR-181c-3p as a critical regulator for adipocytesassociated breast cancer. J Cell Physiol. 2019;234(10):17959-74.

94. Wu Q, Sun S, Li Z, et al. Tumour-originated exosomal miR-155 triggers cancer-associated cachexia to promote tumour progression. Mol Cancer 2018;17(1):155

95. Picon-Ruiz M, Pan C, Drews-Elger K, et al. Interactions between adipocytes and breast Cancer cells stimulate cytokine production and drive Src/Sox2/ miR-302b-mediated malignant progression. Cancer Res. 2016;76(2):491-504.

96. Al-Khalaf HH, Amir M, Al-Mohanna F, et al. Obesity and p16INK4A Downregulation activate breast adipocytes and promote their Protumorigenicity. Mol Cell Biol. 2017. https://doi.org/10.1128/MCB.00101-17.

97. Huang Y, Liu K, Li Q, et al. Exosomes function in tumor immune microenvironment. Adv Exp Med Biol. 2018;1056:109-22.

98. Zhang F, Liu S. Mechanistic insights of adipocyte metabolism in regulating breast cancer progression. Pharmacol Res. 2020;155:104741.

99. Berger NA. Crown-like structures in breast adipose tissue from Normal weight women: important impact. Cancer Prev Res. 2017;10(4):223-5.

100. Arendt LM, McCready J, Keller PJ, et al. Obesity promotes breast Cancer by CCL2-mediated macrophage recruitment and angiogenesis. Cancer Res. 2013;73(19):6080-93.

101. Choi J, Gyamfi J, Jang H, Koo JS. The role of tumor-associated macrophage in breast cancer biology. Histol Histopathol. 2018;33(2):133-45.

102. Yadav NVS, Barcikowski A, Uehana Y, et al. Breast adipocyte co-culture increases the expression of pro-angiogenic factors in macrophages. Front Oncol. 2020;10(April):1-12.

103. Mentoor I, Engelbrecht A-M, van Jaarsveld PJ, Nell T. Chemoresistance: Intricate Interplay Between Breast Tumor Cells and Adipocytes in the Tumor Microenvironment. Front. Endocrinol. (Lausanne). 2018;9(December):1-16.

104. Lehuédé C, Li X, Dauvillier S, et al. Adipocytes promote breast cancer resistance to chemotherapy, a process amplified by obesity: role of the major vault protein (MVP). Breast Cancer Res. 2019;21(1):7

105. Sheng $X$, Parmentier J-H, Tucci J, et al. Adipocytes sequester and metabolize the chemotherapeutic Daunorubicin. Mol Cancer Res. 2017;15(12):1704-13.

106. Delort L, Bougaret L, Cholet J, et al. Hormonal therapy resistance and breast Cancer: involvement of adipocytes and Leptin. Nutrients. 2019;11(12):2839.

107. Bougaret L, Delort L, Billard H, et al. Adipocyte/breast cancer cell crosstalk in obesity interferes with the anti-proliferative efficacy of tamoxifen. PLoS One. 2018;13(2):e0191571

108. Chen $X$, Zha $X$, Chen W, et al. Leptin attenuates the anti-estrogen effect of tamoxifen in breast cancer. Biomed Pharmacother. 2013;67(1):22-30.

109. Bochet L, Meulle A, Imbert S, et al. Cancer-associated adipocytes promotes breast tumor radioresistance. Biochem Biophys Res Commun. 2011:411(1): 102-6.

110. Tang $X$, Wuest M, Benesch MGK, et al. Inhibition of Autotaxin with GLPG1690 increases the efficacy of radiotherapy and chemotherapy in a mouse model of breast Cancer. Mol Cancer Ther. 2020;19(1):63-74.

111. Meng G, Tang X, Yang Z, et al. Implications for breast cancer treatment from increased autotaxin production in adipose tissue after radiotherapy. FASEB J. 2017;31(9):4064-77.

112. Griner ES, Wang JK, Joshi PJ, Nahta R. Mechanisms of AdipocytokineMediated Trastuzumab Resistance in HER2-Positive Breast Cancer Cell Lines. Curr. Pharmacogenomics Person. Med. 2013;11(1):31-41.

113. Duong MN, Cleret A, Matera E-L, et al. Adipose cells promote resistance of breast cancer cells to trastuzumab-mediated antibody-dependent cellular cytotoxicity. Breast Cancer Res. 2015;17(1):57.

114. Wu B, Sun X, Gupta HB, et al. Adipose PD-L1 modulates PD-1/PD-L1 checkpoint blockade immunotherapy efficacy in breast Cancer. Oncoimmunology. 2018;7(11):e1500107.
115. Laloze J, Varin A, Gilhodes J, et al. Cell-assisted lipotransfer: friend or foe in fat grafting? Systematic review and meta-analysis. J Tissue Eng Regen Med. 2018;12(2):e1237-50.

116. Gebremeskel S, Gencarelli J, Gareau AJ, et al. Promotion of primary murine breast Cancer growth and metastasis by adipose-derived stem cells is reduced in the presence of autologous fat graft. Plast Reconstr Surg. 2019; 143(1):137-47

117. Cohen O, Lam G, Karp N, Choi M. Determining the Oncologic Safety of Autologous Fat Grafting as a Reconstructive Modality. Plast. Reconstr. Surg. 2017;140(3):382e-92e.

118. Silva-Vergara C, Fontdevila J, Weshahy O, et al. Breast Cancer recurrence is not increased with Lipofilling reconstruction. Ann Plast Surg. 2017;79(3):243-8.

119. Ryu HS, Lee H-B, Han W, et al. Reduced proliferation in breast cancer cells contacting the neighboring adipocytes in human breast cancer tissues. Breast Cancer Res. 2015;17(1):90.

\section{Publisher's Note}

Springer Nature remains neutral with regard to jurisdictional claims in published maps and institutional affiliations.

Ready to submit your research? Choose BMC and benefit from:

- fast, convenient online submission

- thorough peer review by experienced researchers in your field

- rapid publication on acceptance

- support for research data, including large and complex data types

- gold Open Access which fosters wider collaboration and increased citations

- maximum visibility for your research: over $100 \mathrm{M}$ website views per year

At BMC, research is always in progress.

Learn more biomedcentral.com/submissions 